\title{
沙盘游戏治疗对小学生自尊水平的干预研究 \\ Intervention Study on Self-esteem Level of Primary School Students with Sand Play Therapy
}

$\begin{array}{ccc}\text { 崔美玉 }^{*} & \text { 金龙男 }^{* *} & \text { 金源荣 }^{* * *}[1] \\ \text { Meiyu Cui } & \text { Longnan Jin } & \text { Yuanrong Jin }\end{array}$

摘要: 自尊是个体自我能力和自我价值的整体性感受, 是心理学研究的重要内容之一。良好的自尊不 仅提高学生的自信心和求成行为, 也提高学生的学习能力和社交能力, 而且促进学生身心健康的发展。 小学阶段是自尊水平发展的重要时期, 本研究通过小学生自愿的原则和学生自尊水平的测试结果, 最 终选取 4 名研究对象, 进行十次沙盘游戏治疗干预, 研究结果表明前后测结果有明显的差异。为了验 证沙盘游戏治疗对自尊水平的干预有效性, 3 个月后再对 4 名干预对象进行追踪测试。得出的研究结 论是沙盘游戏治疗对小学生的自尊水平具有良好的干预效果。

关键词: 小学; 自尊水平; 沙盘游戏治疗; 个案干预研究

* 崔美玉, 女, 中国 延边大学师范学院心理学系, 教授

** 金龙男, 男, 中国 延边大学心理健康教育与咨询中心, 专职心理咨询师

*** 金源荣, 女, 中国 心理健康教育教师, 延边职业技术学院 
Journal of Symbols \& Sandplay Therapy, Vol.12 No.2.

\begin{abstract}
Self-esteem is the overall feeling of individual self ability and self-worth, which is one of the important contents of psychological research. Good self-esteem not only improves students self-confidence and achievement behavior, but also improves students' learning ability and social ability, and promotes the development of students' physical and mental health.Primary school is an important period for the development of self-esteem level. In this study, four subjects were selected to conduct ten sand play therapy intervention based on the principle of voluntary behavior of primary school students and the test results of students' self-esteem level. The results showed that there were significant differences between the test results before and after the test.In order to verify the effectiveness of sand play therapy in the intervention of self-esteem level, four subjects were followed up after 3 months. The conclusion is that the sand play therapy has a good intervention effect on the self-esteem level of primary school students.
\end{abstract}

Key words : Primary school; Self-esteem level; Sand play therapy; Case intervention study 
崔美玉 ·金龙男 ·金源荣 / 沙盘游戏治疗对小学生自尊水平的干预研究

\section{I. 绪论}

自尊是幸福感的指标之一, 正确认识自尊有利于学生通过自我调控来提升自己的幸福感以 及各方面的表现。关于自尊的核心含义历来有两种观点: 认知取向认为, 自尊是基于自身品 质而做出的自我判断; 情感取向认为, 自尊是对自身情感的体验和态度。总体而言, 自尊是 一个人在对待自己的态度中表现出的对自我价值的判断, 是个体在社会比较过程中所获得的 对自我价值的积极情感体验。人在不同的发展时期, 影响自尊的主导因素是不同的, 家庭是 影响儿童自尊的主导因素, 随着在校学习和生活的时间增加, 学校因素逐渐占主导地位, 当 个体的主体意识逐渐成熟的时候, 影响自尊的因素就更加复杂。

최정희 (韩国, 2010) 的研究表明: 家庭环境以及父母的教养方式对幼儿的自尊水平的形 成起到关键性作用。幼儿对家庭环境以及教养方式持有接受的态度, 会形成高水平的自尊, 而对家庭环境以及教养方式持有反感的态度, 会导致低水平自尊的形成 ${ }^{[2]}$ 。但定居在延边朝 鲜族自治州的朝鲜族, 因得到独特的地域文化影响, 因大部分父母出国打工, 从小跟父母不 在一起, 在自尊形成关键期在单亲或寄养的环境下成长, 没能及时得到来自双亲的支持, 无 法形成良好的自尊水平。

哈佛大学 TalBen Shahar 博士研究的每个人的自尊发展都会经历三个阶段：依赖型自尊、 独立型自尊和无条件自尊。这三个阶段是渐成的模型。也就是说必须通过第一个层面才能到 达第二个层面, 不能越级, 如果有健康的依赖型自尊, 经过一段时间后就会变成独立型自尊, 如果能培养健康的独立型自尊, 就能达到无条件自尊。依赖型自尊是指他人肯定和表扬的自 尊, 因此依赖型自尊让人渴望得到别的人肯定。依赖型自尊的形成多受他人的影响, 或取决 于他人的比较过程。根据小学生的发展特点, 小学生主观意识尚未健全, 因此行为表现大多 取决于身边的大人, 比起其他年龄阶段的学生而言, 更易受他人的影响, 因此也是建立健康 的依赖型自尊的最佳时期。

[基金项目]2017年吉林省教育科学 “十三五” 规划重点课题《延边地区朝鲜族青少年积极心理品质培 育研究》阶段论文编号: ZD17011. 
Journal of Symbols \& Sandplay Therapy, Vol.12 No.2.

魏晓娟（2016）的研究发现：从小学高年级开始个体的自尊水平随着年级的增高出现下降 趋势。在 2018 年的首都儿童研究所 60 周年学术大会上李辉提到: 随着生活环境和营养改善, 青少年青春期发育比过去提前了约两年。心理会表现出幼稚未成熟的状态, 心理波动大, 变 化快, 逆反心理强, 会发生一系列心理变化。这一时期的学生认知能力在发展, 特别是自我 意识和自我评价能力也在快速的发展，同时同伴交往范围扩大，与同伴亲密程度增加，所有 这些因素使得个性与社会性始终处于发展变化之中, 并且带动了自尊的整体发展。这表明小 学高年级学生已经逐渐步入青春期, 也出现了青春期该有的心理以及行为表现, 因此在小学 高年级开始就应该关注学生的自尊水平，并对低自尊水平的学生及时进行干预。

沙盘游戏治疗是在中小学咨询中深受学生们喜欢的心理咨询方法。沙盘游戏治疗不仅是一 种心理咨询工具, 还是一种运用在心理教育的有效方法。沙盘游戏治疗作为儿童心理和行为 治疗的技术，相比其他咨询方法无法比肩的优势，尤其适合利用于小学阶段的儿童，对于有 效转化小学生的心理健康具有良好的实践效果。新양선（韩国，2019）在通过团体沙盘游戏 治疗对低自尊水平多元文化青少年进行干预的研究中表明，在历经一阶段的沙盘游戏治疗 后, 低自尊水平青少年的自我概念逐渐清晰, 自我认知逐渐明确, 此研究结果说明沙盘游戏 治疗对提高小学生的低自尊水平具有良好的干预效果。

根据教学工作经验, 发现自尊水平较低的学生在课堂表现中, 过于顾忌他人对自己的看法, 难以表达自己内心的真实感受与想法。因缺乏对自己的肯定, 在学习上学业自我效能感较低, 在人际关系上主动性较差等问题。这些问题中自尊水平起到决定性作用，因此提高小学生的 低自尊水平极为关键。

本文利用沙盘游戏治疗对低自尊水平的学生进行十次干预, 以期探究学生低自尊水平的原 因, 提高自尊水平并促进学生的健康成长。 


\section{II. 研究方法}

\section{1. 研究对象}

利用《儿童自尊量表》对延吉市某校五年级和六年级学生进行测试, 根据学生的测评结果、 教师访谈以及父母访谈为前提选取了干预对象, 在这基础上采取学生自愿的原则最终确定了 4 名咨询对象。选取的 4 名来访者的自尊水平在各维度上的最低分是不同的。具体情况请如 下:

\section{1) 来访者 $\mathrm{F}$ 学生}

男, 12 岁,小学五年级学生,在自尊水平自评前测量表结果显示该学生在能力维度 $(M=1.67)$ 上得分最低。通过前期调查了解到该学生父亲是工人，母亲是家庭主妇，哥哥就读于初中一 年级。因父亲的家暴现与母亲离婚, $\mathrm{F}$ 学生与父亲共同居住, 哥哥跟母亲共同居住。F 学生 对父亲有不安情绪, 对母亲只带哥哥走的行为有抱怨。学习成绩不理想, 导致 $\mathrm{F}$ 学生对自身 学习能力上的自尊表现较差, 对自己能力上的评价较低, 经常说 “我无所事事” 等对自身能 力持有消极的态度。

\section{2) 来访者 $\mathrm{P}$ 学生}

男, 13 岁,小学六年级学生,在自尊水平自评前测量表结果显示该学生在外表维度 $(\mathrm{M}=2.00)$ 上得分最低。由于从小父母去国外打工, 一直与祖父母一起生活, 弟弟就读于小学 3 年级。 $P$ 学生非常希望成为有人气的焦点人物, 但由于 $P$ 学生的个子比其他学生矮一些, 认为他的 个子是在他成为 “人气王” 的道路上的绊脚石。因此在自身的外表上非常缺乏自信心，P 学 生在自己的外表上持有较低的自尊感。导致在学校很少与他人交流。在同伴关系中，因为小 事很容易发火，耐性较弱，对每件事都持消极的态度。 


\section{3）来访者 $Z$ 学生}

女, 12 岁, 小学五年级学生, 独生子, 在自尊水平自评前测量表结果显示该学生体育运 动维度 $(M=2.30)$ 上得分最低。 $Z$ 学生的性格非常内向, 体力较弱, 讨厌尝试新鲜事物, 主 动性较差。虽然 $\mathrm{Z}$ 学生非常想在体育运动中有良好的表现, 但由于天生身体条件以及性格特 征, 导致 Z 学生不愿意主动尝试, 愿望与实际矛盾的现象, 导致在体育运动方面持有较低的 自尊水平。

\section{4）来访者 $\mathrm{H}$ 学生}

女, 13 岁, 小学六年级学生, 独生子, 在自尊水平自评前测量表结果显示该学生纪律 $(M=3.00)$ 以及成就感维度（ $M=3.00 ）$ 上得分最低。由于 $H$ 学生在成长过程中得到了父母的 溺爱, 大多数情况下父母都会遵循 $H$ 学生的意愿, 但学校是具有一定纪律与规则的地方, 未 能将家庭和学校的里的自我管理表现转换得很好, 因此常常有人评价 $\mathrm{H}$ 学生纪律较差, 导致 在纪律上的自尊水平较低; 因为从小受到父母的关爱较多, 非常渴望得到来自他人的友好评 价, 但现实生活中未能在此方面得到满足, 导致 $\mathrm{H}$ 学生早成就感维度上的得分较低。

\section{2. 调查工具}

《儿童自尊量表》是由魏运华 1997 年编制的自评量表, 用来测量个体的总体自尊状况。 儿童自尊量表分 5 个分量表组成, 分别是: 外表, 体育运动, 能力, 成就感, 纪律, 公德与 助人。量表共有 26 个题目, 所有题目按符合程度由弱到强的 1-5 分计分。反向计分题则相 反, 反向计分题目有: $3,4,10,17,20,22,23,26$ 。研究表明该量表具有较高的信效 度, a 系数 $0.68-0.77$ 。 
崔美玉 ·金龙男 ·金源荣 / 沙盘游戏治疗对小学生自尊水平的干预研究

\section{3. 研究程序}

首先, 篮选被试后, 了解每个案自尊水平情况, 分别对每例个案的家长和班主任进行访谈, 了解个案的基本信息以及具体表现。

其次, 对 4 例个案分别在不同时间点进行沙盘游戏治疗, 每个个案每周两次, 每次 50-60 分钟，干预次数依据每个个案的情况而定。

再次, 将个案在每次沙盘作品后的反应和感受、咨询师对沙盘游戏治疗过程的记录以及每 次沙盘结束后咨询师对被试的访谈作为作品分析的参考依据, 整合个案每次沙盘游戏治疗的 相关资料。

最后, 沙盘游戏结束后, 再次对 4 例个案进行儿童自尊量表问卷调查, 比较 4 例个案在前 后测的自尊水平得分差异，以每个案在沙盘游戏治疗中的动沙情况和沙盘游戏治疗前后班主 任和家长的访谈结果对比以及前后测得分差异作为效果评估。

\section{4. 沙盘游戏治疗干预方案设计}

本研究根据 Laura Ruth Bowyer (1970) 的沙盘游戏治疗的发展阶段, 将整个咨询过程分为 咨询初期阶段, 咨询中期阶段和咨询终结阶段三部分。本研究准备以及实施期间为一学期 16 周, 考虑到前期准备阶段工作以及学校日程安排, 初步将每位来访者的咨询次数定为 10 期, 根据实际访谈效果, 有弹性的调节咨询次数。为确保高效的咨询效果, 将来访者人数定 为咨询师足够可控制的 4 人。根据上述理论初步制定了沙盘游戏治疗干预研究的设计方案, 但根据个体差异实施阶段的每一个步骤会有略微的调整, 以下是沙盘游戏治疗干预研究设 计: 如表 1 。 
Journal of Symbols \& Sandplay Therapy, Vol.12 No.2.

表 1 . 沙盘游戏治疗干预研究设计

\begin{tabular}{|c|c|c|}
\hline & 干预前测评 & 征得来访者同意后对四名来访者进行量表评估。 \\
\hline 咨 & 第一期 & \multirow{6}{*}{$\begin{array}{l}\text { 本阶段是在整体的咨询过程中打造良好基础的关键时期。在此阶段向来访者介绍沙盘游 } \\
\text { 戏治疗中的各种相关事项, 有助于促进来访者能够更加尽快投入到沙盘游戏治疗中。还 } \\
\text { 能引导来访者在放松愉悦的氛围下进行咨询, 有助于建立良好的咨访关系, 这也是咨询 } \\
\text { 初期应做到的关键工作。 }\end{array}$} \\
\hline 询 & 沙盘游戏 & \\
\hline 初 & 治疗过程 & \\
\hline 期 & 第二期 & \\
\hline 阶 & 沙盘游戏 & \\
\hline 段 & 治疗过程 & \\
\hline \multirow{18}{*}{$\begin{array}{l}\text { 咨 } \\
\text { 询 } \\
\text { 中 } \\
\text { 期 } \\
\text { 阶 } \\
\text { 段 }\end{array}$} & 第三期 & \multirow{18}{*}{$\begin{array}{l}\text { 在达成咨询初期阶段制定的咨询目标时, 就会进入咨询的中期阶段。有时在学生咨询中 } \\
\text { 可能会很难分辨咨询的初期与中级阶段, 根据来访者的困扰对来访者的影响程度, 应出 } \\
\text { 现在中期阶段的表现与变化可能会出现在咨询的初期阶段, 也有可能根据整体的咨询居 } \\
\text { 期, 出现很难分辨咨询的中期与初期的现象。但如果咨询的初期阶段是来访者与咨询师 } \\
\text { 建立良好的咨访关系, 并透露出自身困扰的阶段, 那么中期阶段就是进一步探索来访者 } \\
\text { 内心深处无意识领域中的欲望和冲动, 并且通过一段时间的咨询来访者的行为有所变化 } \\
\text { 的阶段。 }\end{array}$} \\
\hline & 沙盘游戏 & \\
\hline & 治疗过程 & \\
\hline & 第四期 & \\
\hline & 沙盘游戏 & \\
\hline & 治疗过程 & \\
\hline & 第五期 & \\
\hline & 沙盘游戏 & \\
\hline & 治疗过程 & \\
\hline & 第六期 & \\
\hline & 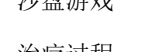 & \\
\hline & 治预过枉 & \\
\hline & 第七期 & \\
\hline & 沙盘游戏 & \\
\hline & 治疗过程 & \\
\hline & 第八期 & \\
\hline & 沙盘游戏 & \\
\hline & 治疗过程 & \\
\hline 咨 & 第九期 & \multirow{6}{*}{$\begin{array}{l}\text { 在本结阶段步入了咨询的后期。来访者表现出了各种心理及行为变化。在咨询中一直困 } \\
\text { 扰来访者的核心问题相关的内容逐渐减少, 并转化为积极又有建设性的活动。随着咨询 } \\
\text { 的逐步开展, 会让来访者体验到适当的自信心, 洞察力, 安全感等积极的心理体验。这 } \\
\text { 也意味着来访者不再过多依赖咨询, 具有一定的独立解决问题的能力。这也是咨询进入 } \\
\text { 了终结阶段的重要信号。 }\end{array}$} \\
\hline 询 & 沙盘游戏 & \\
\hline 终 & 治疗过程 & \\
\hline 结 & 第十期 & \\
\hline 阶 & 沙盘游戏 & \\
\hline \multirow[t]{3}{*}{ 段 } & 治疗过程 & \\
\hline & 干预后测评 & 干预结束后再次进行量表评估和对父母和班主任进行访谈。 \\
\hline & 追踪测评 & 三个月后再次进行量表评估。 \\
\hline
\end{tabular}




\section{III. 沙盘游戏治疗干预过程分析}

\section{1. 沙盘游戏治疗过程分析}

\section{1) 第一次沙盘游戏治疗干预过程分析}

四名来访者第一次进行沙盘游戏治疗时，由于初次接触沙盘，对沙盘比较陌生，表现出拘 谨和紧张的状态。沙盘游戏治疗中, 最初的沙盘作品在整个治疗过程中具有特别的意义。 $\mathrm{F}$ 学生制作的是两个军队对立的场景; P 学生是把沙具随机摆放在沙盘中，并表示沙具之间没

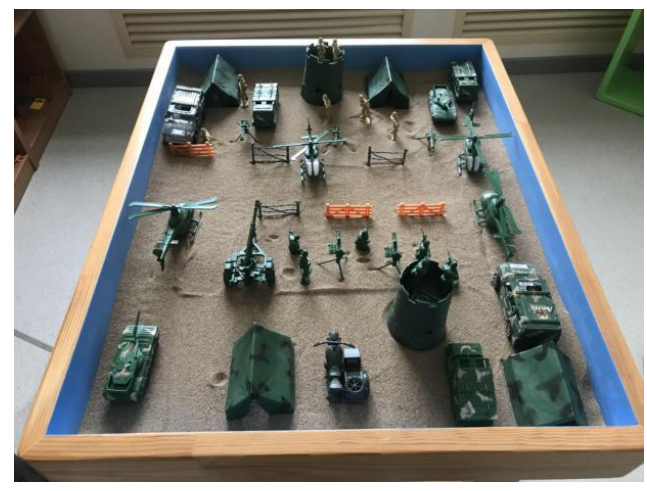

F1

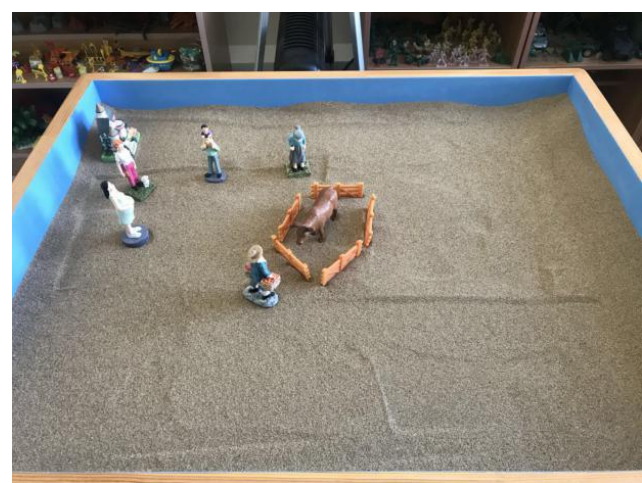

Z1

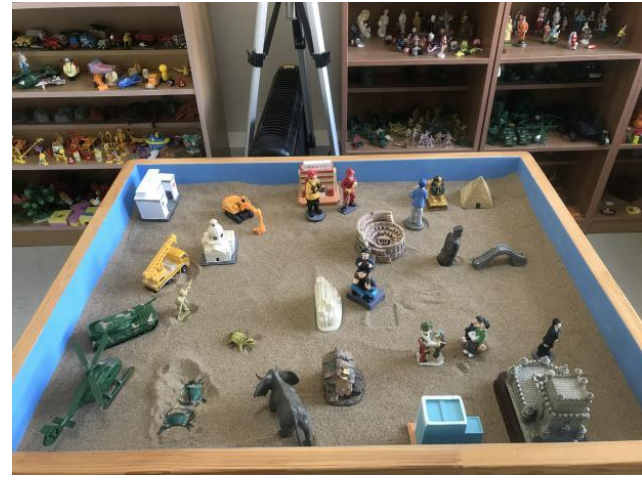

P1

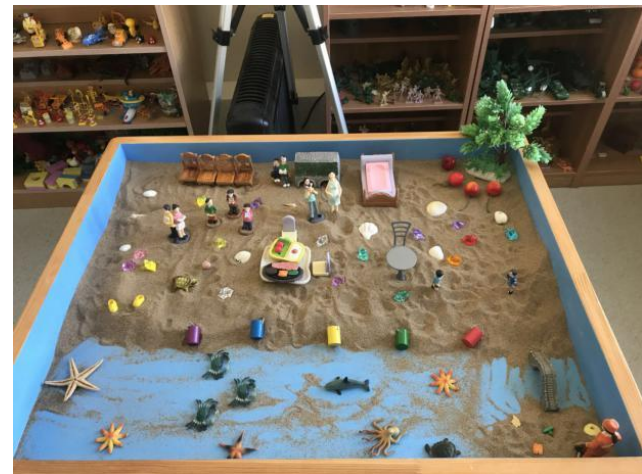

$\mathrm{H} 1$

图 3-1. 第一期沙盘图 
Journal of Symbols \& Sandplay Therapy, Vol.12 No.2.

有相关性; Z 学生的沙盘是想象居住在农村祖父母家的院子制作的; H 学生制作了自己想象 中的大海的场景。请看图 3-1。

\section{第一期沙盘分析:}

$\mathrm{F}$ 学生: 选择了士兵, 并放在沙盘的中下方位置, 以士兵为中心逐渐在周围布置了其他沙 具。最终, 整体沙盘呈现内容是两个部队对峙的情境。战争是解散和再结合的过程, 善与恶 的冲突, 象征着实现统一 ${ }^{[3]}$ 。 F 学生指着左下角的坦克自述到 “在沙盘里最让我满意的是左 下方的坦克。因为坦克不仅震慑威力大, 还有很坚实的外壳。“如果我在沙盘里的某个部位 的话, 我会在坦克里, 因为坦克可以保护我, 但我觉得坦克保护作用也不是绝对的。” 在与 F 学生进一步交流中了解到, 坦克的形象让 F 学生联想到了母亲。谈到这里, F 学生默默地 留起了眼泪。Grunwald 的空间图示象征, 左下视为集体潜意识领域 ${ }^{[4]}$ 。把坦克放置左下方, 自己在坦克里, 而坦克让他联想到了母亲, 表达出对母亲所带来的不安以及无奈、无助的状 态。 F 学生边哭边谈到, 父亲酒后经常砸坏家具家电, 而 $\mathrm{F}$ 学生和母亲, 哥哥都提心吊胆地 生活在家庭暴力中。由此 $\mathrm{F}$ 学生的生活处在紧张状态。沙盘作品的上下对称也表达出紧张的 情绪。

$P$ 学生: P 学生说: “我觉得我选的这些沙具很酷, 我比较喜欢长得非常独特有个性的建筑 物，在沙盘里我最喜欢的是金字塔。” 沙盘的右上角表示目标与理想，在沙盘右上角的部分 放置了一个金字塔。金字塔是世界的中心，在 Aztecan 文化（墨西哥中央高原上发达的靛蓝 文明) 中金字塔是坟墓, 是供奉神灵的神殿 ${ }^{[5]}$ 。在沙盘中可以推断出, 金字塔的出现, 是典 型的自我的象征。尽管沙具之间的布局没有任何联系, 在第一期沙盘中就出现了自我的象征, 说明 P 学生在潜意识中, 有着对自我探索了解的欲望。

$Z$ 学生: 在农村会有很多有趣的事情发生, 所以我非常喜欢那里, 也会感到非常的安逸舒

\footnotetext{
[3] 진쿠퍼 (J. C. Cooper). 세계문화상징사[M]. 서울:까치 (韩国) 1994.

[4] 하은혜, 곽진영, 김효식. 미술치료의 이해[M]. 서울:교육문화출판미디어그룹학지사 (韩国) , 2019.

[5] 진쿠퍼 (J.C.Cooper). 세계문화상징사[M]. 서울:까치 (韩国) , 1994.
} 
适。” 可以看出 Z 学生想要表达自己的内心, 但表现非常小心谨慎, 很难做出任何选择。Z 学生指着牛的沙具说到 “看着中间的牛, 让我觉得很孤独, 我最近也感到很孤独。因为现在 家里就只有我一个孩子。但过几天姨妈的孩子马上要出生, 我很担心对我的关心会被抢走”。 说沙盘里的一头牛看起来孤独, 其实是通过沙盘中的牛将自身对马上出生的弟弟感到担心、 不安情绪投射出来的一个结果。虽然是单纯地对孤独的投射, 但从分析心理学上看, 牛耕田 有力量, 看起来很驯顺, 却也有固执印象。在 $Z$ 的沙盘中, 牛被困在围栏里, 表示固执, 也 是内在固有的一面, 不过只是封印在内心深处, 还未得以释放。

$\mathrm{H}$ 学生: 自述到, “蓝色部分是大海, 沙子表示沙滩, 沙滩上有很多人正在玩要, 他们尽 情享受着。右下角有一座长长的桥联系着沙滩与另一座小岛, 小岛上有一位清洁工正在做打 扫工作。” 海洋象征着混乱、无形和不停止的运动 ${ }^{[1]}$ 。在做第一个沙盘时, $\mathrm{H}$ 把自己内在的混 乱、寂寞、孤独的情绪投射在沙盘。右下方意识领域逐渐扩展, 连接两端的桥意味着连接各 领域的作用。在 $H$ 学生制作沙盘时可以看到, 经常移动沙盘中的沙具的位置, 反复更换放在 沙盘里的沙具。

\section{2）第二次沙盘游戏治疗干预过程分析}

第二次来到沙盘游戏治疗室之后, 四名来访者的表现都不尽相同: F 学生和 Z 学生表现出 犹豫、紧张的状态; P 学生和 H 学生看起来不再犹豫, 觉得很快适应整个过程。引导来访者 能够自由自在地摆放沙具后, F 学生制作的是城市道路的情景; P 学生还是毫无联系地随机 摆放; Z 学生制作的是根据最近散步时的情境制作的沙盘; $\mathrm{H}$ 学生是将沙子向两边移动, 使 沙盘的蓝色底部呈现出来, 并表示这是一条路, 呈现出两边对立的场景。 


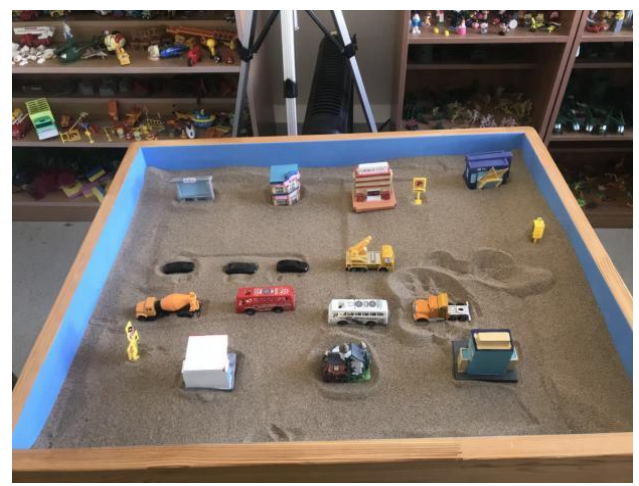

F2

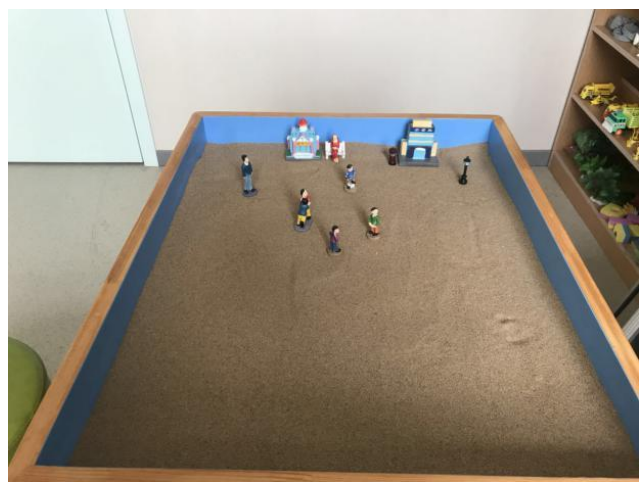

Z2

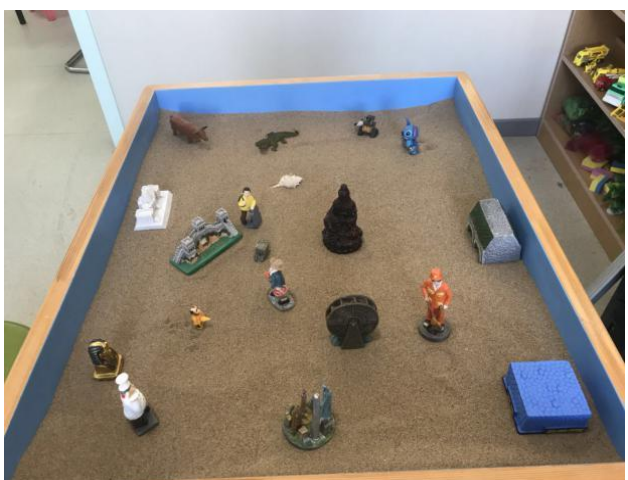

P2

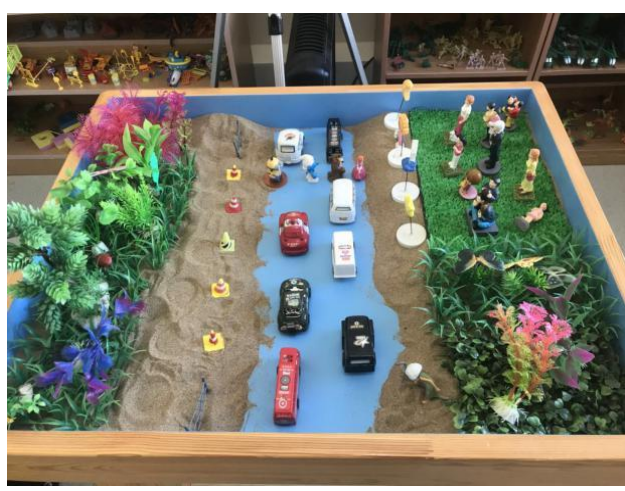

$\mathrm{H} 2$

图 3-2. 第二期沙盘图

\section{第二期沙盘分析：}

$\mathrm{F}$ 学生: 来访者自述到, “我最喜欢的是三个黑色轿车, 因为跟其他车辆沙具比较, 黑色轿 车体积较小, 看起来非常可爱。” 行驶的车辆象征原动力, 其中在施工现场使用的卡车、混 凝土搅拌车以及大巴士的方向从右向左, 说明进入潜意识的形象表现。说明在潜意识中直面 消极经验中的焦虑、不安、胆怯和父母的消极等情绪。卡车的象征很多, 在沙盘作品中卡车 象征着拉力 ${ }^{[6]}$, 卡车的方向是从左到右, 从潜意识到意识的方向行驶。根据沙盘内容, 进一 步交流中了解到, 以前 $\mathrm{F}$ 学生平常的大小事务都是在母亲的指导下完成的, 导致独立性较差,

${ }^{[6]}$ 魏广东. 沙盘游戏治疗象征手册 [M]. 北京: 中国石化出版社, 2018. 
无法独自选择或决定一些事物。并且经常对自己进行消极的评价。例如, 经常说 “我很笨”、 “什么事都做不好”等评价。可以推断出与焦虑、萎缩、较低的自尊感有关联。

$\mathrm{P}$ 学生: P 学生讲到, 在选沙具时首先会考虑有趣的沙具, 其次是较酷的沙具。做完沙盘之 后, 看着自己的作品说, 感觉自己选的沙具很特别也很喜欢, 并说平常也很喜欢这样有个性 特别的东西。狮身人面像出现在左下方潜意识领域。在埃及神话中的狮身人面像是混沌的, 被称为众神之父 ${ }^{[7]}$ 。最初, 它表现为象征混乱状态的拟人化。但是并不是消极的, 可以视为 进入较深的潜意识的过程，该潜意识部分是尚未被发现并且尚未组织起来的领域。在咨询中 说道, 看着沙盘中上方穿黄色衣服的学生, 让他想起了 4 年级时的事情。P 学生讲到: “那时 有同学在教室遗失了钱, 当时只有我在教室, 所以全班同学都怀疑我是小偷, 真不是我拿的 钱, 但所有人都不相信我。当时我觉得很无奈, 很冤枉, 之后跟同学们的相处更难了。这件 事后, 跟朋友出现小小的意见分歧也会让我丧失理性地暴躁起来, 他们都说我的反应太敏感 了”。来访者的此现象与以往研究结果相似 ${ }^{[8]}$, 可以看作为低自尊现象。

$Z$ 学生: $Z$ 学生自述到, “我想展示的是散步的情境, 在这个沙盘中, 我最喜欢并且让我感 到最舒服的是最上放的那个坐在长発上的女生。虽然白色登子和坐在上边的女生是两个分开 的沙具, 但把女生放到発子上时, 我感觉到两个好像原来就是一体的非常合适, 很喜欢这种 恰到好处, 非常合适的感觉。” 沙盘仍然表现出寂寞。但是在潜意识的领域的左侧的方向, 显现出人格化的要素。而目前在意识领域还未完全体现出。可以看出沙盘整体沙子的分布是 均匀的, 沙子可以视为精神的深度, 可以看作是逐渐意识化的象征。 $Z$ 学生说是喜欢坐在椅 子上的女孩。感觉位置安排很好, 也投射出要准确无误的性格表现。在进一步的咨询中, 知 道非常保守, 喜欢按部就班做事。并讲述了与母亲之间的故事, 讲到: “之前因为一些事情, 妈妈对我有了一些误解。但是不管怎么解释, 妈妈就是不相信我, 我感到非常委屈无奈。自

[7] 이부영. 이집트 신화[M]. 서울: 해바라기 (韩国), 2001.

${ }^{[8]}$ 沈贵兰. 城市小学儿童自尊异质性背景下的社交焦虑在自尊和同伴关系间的中介作用 [D]. 成都: 四 川师范大学, 2017. 
Journal of Symbols \& Sandplay Therapy, Vol.12 No.2.

从那件事之后, 我认为在发生矛盾时, 不需要对别人进行解释, 即使解释了, 他也不一定会 理解你。” 在咨询中了解到, $Z$ 学生很少主动表达内心的感受与自己的感情, 处于非常被动 的状态。给人一种 “好孩子” 印象的学生。在言谈举止中，可以看出她非常细心。

$\mathrm{H}$ 学生：H 学生自述到, “路的左右侧是对称的, 左侧是一片森林, 里面有很多危险的昆虫 动物。而右侧是相反的。右侧里有很多人和美好的事物。右下方到路边有一位杵着拐杖的老 奶奶。” H 学生在制作沙盘作品时, 表现出毫不犹豫的样子。将沙盘的整体试图以对称的形 式表现出来, 并且将沙具有序地进行排列。右下角出现了一位老人。老人象征着智慧老人的 原型 ${ }^{[9]}$, 智慧老人的原型在荣格的生活中发挥了重要的补偿作用。完全明智或了解一切的感 觉是一种体验自信的很好的过程。与其他来访者不同的是 $\mathrm{H}$ 学生一直都是两手满满地一次性 拿着沙具回来，并在沙盘中摆放沙具，试图尝试两边对称。在与咨询师的交流中，H 学生表 示：“不想谈论有关自己的事情。” 并对有关自己的提问，以古怪的行为表情表现出回避的反 应。经常移动沙具的位置的表现，是从 $\mathrm{H}$ 学生想表达的欲望和没有自信的不安的情绪中产生 的。对通过沙盘游戏治疗体现出了潜意识中的不安的情绪表现。

\section{3）第三次沙盘游戏治疗干预过程分析}

从第三期开始, $\mathrm{F}$ 学生和 $\mathrm{Z}$ 学生也对沙盘游戏治疗过程表现得更加适应, 看咨询师眼色行 事或萎缩的非语言行为有所减少, 在选择沙具的过程中, 表现出更积极的探索。 F 学生制作 的是机场; P 学生还是随机摆放沙具, 但是部分沙具和沙具之间产生了联系; Z 学生制作的 是公园的场景，可以看出沙盘中的沙具数量增多; $\mathrm{H}$ 学生制作的是医院的场景。

\section{第三期沙盘分析：}

$\mathrm{F}$ 学生：虽然在选沙具时犹豫不决，拿起放下时也很小心翼翼，但思考的时间比前两期咨

${ }^{[9]}$ 하은혜, 곽진영, 김효식. 미술치료의

이해 [M]. 서울: 교육문화출판미디어그룹학지사 (韩国), 2019. 


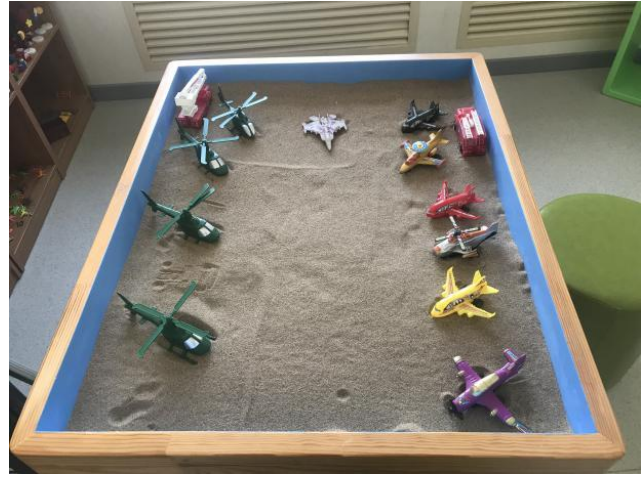

F3

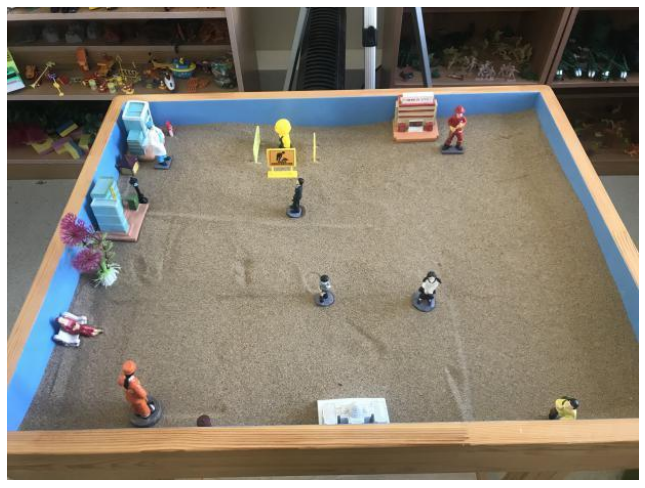

Z3

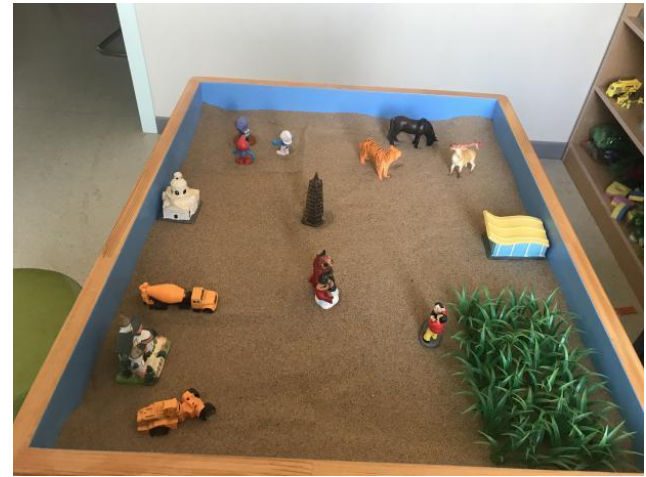

P3

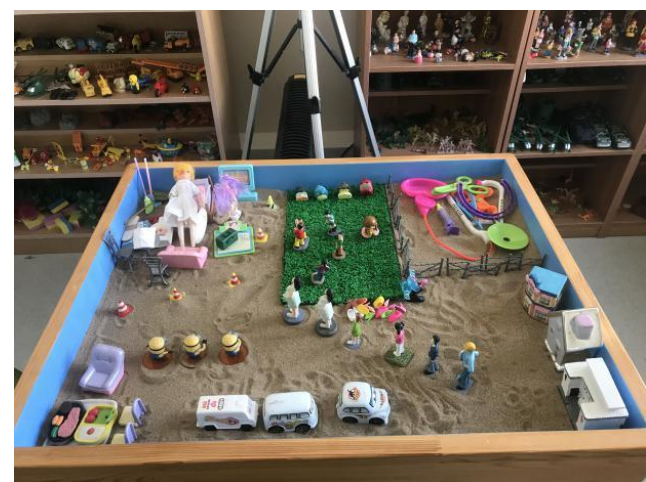

H3

图 3-3. 第三期沙盘图

询有所缩短。下方的空心圆点可看作为 “自我”, “自我” 的出现是有意义的, 但是 F 学生的 “自我”没有具体的沙具进行表征, 而是在平整的沙子中留下一个空心圆的印记。由此可见, $\mathrm{F}$ 学生对 “自我” 没有形成准确的认识。呈现的是机场里直升机和飞机在举行比赛的情境。 为避免比赛时出现突发状况, $\mathrm{F}$ 学生备了消防车, 以防发生火灾引起人员伤亡。荣格分析心 理学中沙盘的上方表示精神领域, 在上方放置有消防车和云梯车, 象征着 $\mathrm{F}$ 学生在潜意识中 渴望得到外界帮助。飞机是推进力的象征, 所有飞机的方向都指向着空心圆点, 说明尝试进 一步了解 “自我”。 
Journal of Symbols \& Sandplay Therapy, Vol.12 No.2.

$\mathrm{P}$ 学生: P 学生说上次咨询完回家后, 自己想了很多。发火的情绪是从哪里来的, 怎样才 能很好地控制自己的情绪。虽然想了很久，也想了很多，但是没有找到合适正确的方法。可 以看出, 咨询对 $\mathrm{P}$ 学生的影响是较大的。本次咨询中, 首先选择了草坪放到了右下角部分, 并选择了三个动物沙具放在沙盘的右上角。沙盘作品中首次出现了植物, 植物象征着死亡和 复活、生命力和生命循环 ${ }^{[10]}$ 。这个循环的映像被视为是通过死亡而增长的象征。右上方出现 了三个动物的沙具, 动物中有肉食动物和草食动物, 可以看作为性格的多样性。本次沙盘中 的动物可以看作为本能和欲望的象征。这次是第一次在 $\mathrm{P}$ 学生的沙盘作品中, 找到了一些沙 具之间的联系点。左下方的混泥土搅拌车和拖拉机，虽然这两个沙具出现是积极的，但是还 没开始工作，而是在准备阶段。右上方是目标领域，可以看作为对自己的探索和对成长欲望 的表现。在咨询师的引导下, 进一步感受了自己完成的作品, 并讲到： “看着我的作品, 总 觉得每个沙具之间缺乏联系, 这让我对沙盘作品感到非常的遗憾, 但对沙盘整体我还是很满 意的。”

$\mathrm{Z}$ 学生: 在第三期咨询中依然出现了第二期的坐在长発上的女孩沙具, $\mathrm{Z}$ 学生自述到: “这 个是一个广场, 我坐在广场的一角, 就是右下角这个部分, 看着广场里的其他孩子尽情玩要, 觉得他们玩得很开心, 很有趣。” 第二期相同, 出现了玩要的孩子沙具, 但选择的自我像 确实是安安静静地坐在椅子上的女孩沙具。这里玩要的孩子沙具指的是 “永远的少年” 称为 “Puer aeternus”, “永远的少年” 是一个古代神的名字。荣格曾解释：Puer 等意味着心里 幼儿性 ${ }^{[1]}$ 。有时这可以看作是像顽皮一样天真烂漫, 有时还可以表达出没有想法、冲动的必 要性的象征性映象。同是孩子, 在沙盘中呈现的自己确是安安静静的形象, 而其他同龄人是 天真无邪玩要的状态, 并且非常欣慰地观看他们。 $Z$ 学生也喜欢他们的状态, 并非常向往, 说明通过沙盘对现实中无法实现的自我进行替代性补偿。医生、消防、清洁工和工人的出现, 就像人体中的白血球, 能够与病菌抗争的积极因素一一内在的力量逐渐转化为人格化的表

[10] 魏广东. 沙盘游戏治疗象征手册 [M]. 北京: 中国石化出版社, 2018.

[11] 홍숙기. 마리 루제이 폰프란츠[M]. 서울: 한국융연구원 (韩国), 2017. 
现。结束制作沙盘后, 表示自己平时一直是没有勇气, 自尊感很低, 主要讲述了自己的缺点。 来访者主动讲述自己的缺点来自我开放, 初步确定了建立咨访关系。

$\mathrm{H}$ 学生: 与往常一样在选择沙具时会一股脑选完, 再进行位置的摆设。制作沙盘作品时, 非常投入其中, 常常忘记或忽略咨询师提出的问题, 沉浸在自己的世界里。常常会一边介绍 沙盘, 一边重新移动沙具。自述到: “左上角这里是医院病房, 因为我的胳膊受伤了, 所以 我躺在病床上，中间那一排人是来看我的人。右上角的围栏里有很多医疗工具。”在介绍完 之后, 说一部分的沙具好像看起来不是很合适, 说着从沙盘中把沙具移出。沙盘中可以看到 病床上躺着的小女孩，众多人物的能量流向这小女孩。沙盘可以投射出自己内心世界，把自 己生病时的情景投射在无力躺在床上的小女孩沙具。而其他人物象征着观望自己内心世界的 多种人格。右上方为目标领域, 可以看出这是 $\mathrm{H}$ 学生用各种医院设备治疗自己的映像, 但是 它被栅栏挡住了。

\section{4）第四次沙盘游戏治疗干预过程分析}

到第四期沙盘, 四名来访者都适应沙盘游戏, 并积极地在过程中探索。在本期, F 学生制 作的是复杂的城市; P 学生选择的沙具都是自己平时喜欢的建筑模型和沙具; Z 学生制作了 田园的情景; $H$ 学生制作的是周围被建筑围着的海洋。

\section{第四期沙盘分析:}

$\mathrm{F}$ 学生: 在沙盘作品中, 表现了用自己喜欢的挖掘机挖出工地沙子的情境, 挖掘机所处的 位置正是沙盘中表示的潜意识领域左下方。通过这一表现可以看出, F 学生有意地去探索自 身尚未发现的 “自我” , 并呈现在意识领域的欲望。自述到: “这是一座建设中的城市, 我 最喜欢其中的大卡车，我也不太清楚为什么喜欢，但把沙子装到大卡车里时，我感到了莫名 的舒服有趣。” 在左下角部分进行强调加工的表现，说明在潜意识中迈出了自己内在的积极 和创造的可能性。在摆弄沙具制作沙盘作品的过程中, 观察到 $\mathrm{F}$ 学生对自己的自信心非常低 


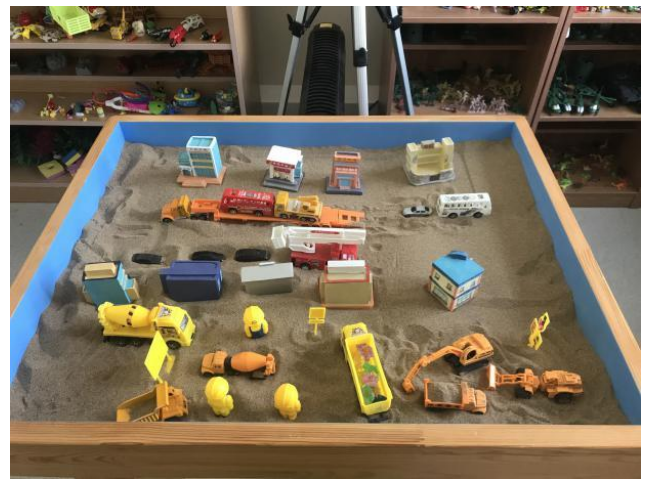

F4

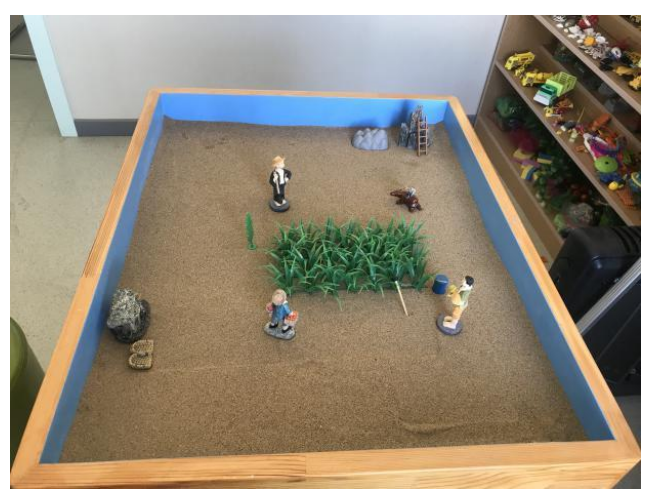

Z4

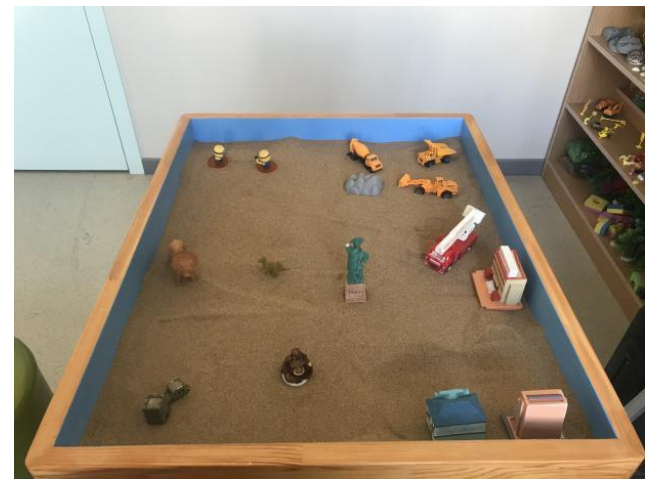

P4

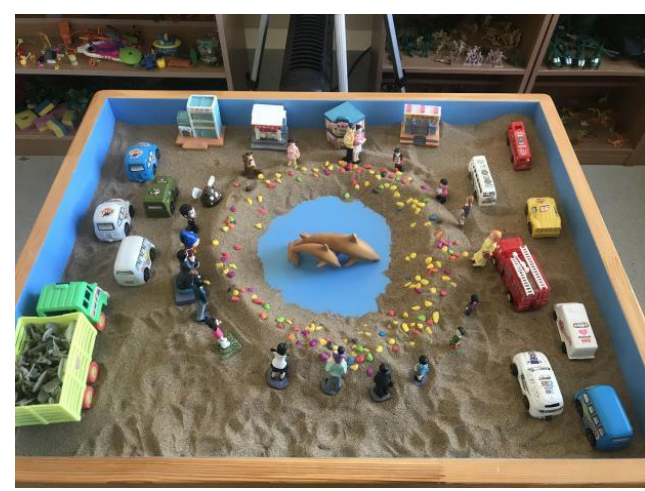

$\mathrm{H} 4$

图 3-4. 第四期沙盘图

下, 他总是觉得自己无所作为, 表现非常差劲, 很少受到来自外界的表扬和肯定。在咨询过 程中, 咨询师有意抓住 $\mathrm{F}$ 学生的优秀表现进行赞扬时, 会对咨询师的赞扬感到惊讶, 甚至对 其真实性感到质疑。

$P$ 学生: 沙盘中央出现了自由女神像, 自由女神像是对争取自由而斗争的象征 ${ }^{[12]}$ 。第三期 出现在左下角的施工场景, 在这一期出现右上角部分, 并且施工情境的呈现, 在沙盘的占用

${ }^{[12]}$ 손영호. 마이너리티역사-혹은 자유의 여신상: 살림지식총서 [M] : 서울: 살림출판사, 2003. 
比例也比之前多了些。施工现场出现在表示潜意识领域的左下角, 并且呈现的施工现场处在 施工的准备阶段。表示在潜意识里, 有着对 “自我” 探索的苗头以及意愿, 但未进行真正的 探索。在本期的沙盘作品中, 施工情境移到了表示目标的右上方, 并且施工现场处在正在施 工的阶段。这象征着 P 学生正在通过沙盘, 有意识地去进行 “自我” 探索。卡车、搅拌混凝 土和拖拉机正忙于工作, 这是选择土壤并去除不必要的元素以建造新的工作。评价自己说道, 因为自己的暴躁和懒惰的性格, 导致无法成为受他人欢迎的人。说道, 如果自己有改变现状 的想法, 再加上周围他人的帮助, 改掉不良性格与习惯, 很有可能达成自己的希望, 成为一 个受他人欢迎的人。

$Z$ 学生: 在这期中, $Z$ 学生首先选择了植物放在沙盘的正中央, 其次以植物为中心, 在旁 边放了 3 个人以及牛等沙具, 3 个人的位置大致呈现 3 角形。沙盘的中央出现了植物, 并可 以看出有 3 个人在精心管理着这些植物。“ “ 3 ” 这个数字有许多象征, 是具有安全感并表示 完美的数字, 而且三角形的构图也象征着不会摔倒的安全性。草地旁边出现了一头小牛, 与 第一期咨询中出现的 “牛” 沙具时不一样的状态, 它不再是囚禁并拘禁的状态。这一期的牛 背上还有一个吹着笛子的男孩儿, 可以看出他们的状态是放松的。说明 $\mathrm{Z}$ 学生的状态比之前 放松了许多, 克制自己的倾向也有所减少, 试图从多方面发觉自己。自述到, 这里是农村田 野, 这里的三个人在辛苦劳作, 尽心尽意地耕田, 插秧。对今天制作的这个作品非常满意, 还有一些小成就感。这从 $\mathrm{Z}$ 学生评价自己的语句中也可以看出。

$\mathrm{H}$ 学生: 在沙盘中间画一个圆, 然后将沙子移到一边, 使其看起来像一个圆形的大海。圆 的有着全体性、完全性等象征 ${ }^{[13]}$ 。在分析心理学里将这种映像称为 “自我”。并不是所有的 “圆” 都象征着 “自我” , 但通过 H 学生的 “圆” 在沙盘中呈现的位置, 并结合 H 学生的描 述, 可以进一步确定, 在沙盘中央部分的 “圆” 象征着自身。表示中间需要有什么东西, 并 到沙具柜中取一对海豚, 说这两只海豚在大海里自由地玩要。海豚有救世主、引导者和救助

${ }^{[13]}$ 진쿠퍼 (J. C. Cooper). 세계문화상징사[M]. 서울:까치 (韩国), 1994. 
Journal of Symbols \& Sandplay Therapy, Vol.12 No.2.

者的象征 ${ }^{[1]}$ 。如果将这些象征结合, 则可以看出 $\mathrm{H}$ 学生通过潜意识心理工作, 投射并表达自 己固有的救世主原型。

\section{5）第五次沙盘游戏治疗干预过程分析}

第五期沙盘中, F 学生制作的是自己想象中的公园; P 学生的沙盘中有河、海、城市、农 村, 还有动物, 值得肯定的是他的沙盘中沙具之间的联系增加; $Z$ 学生制作的也是动物园情 景; H 学生把沙盘分成两半分别表示为屋内和屋外。

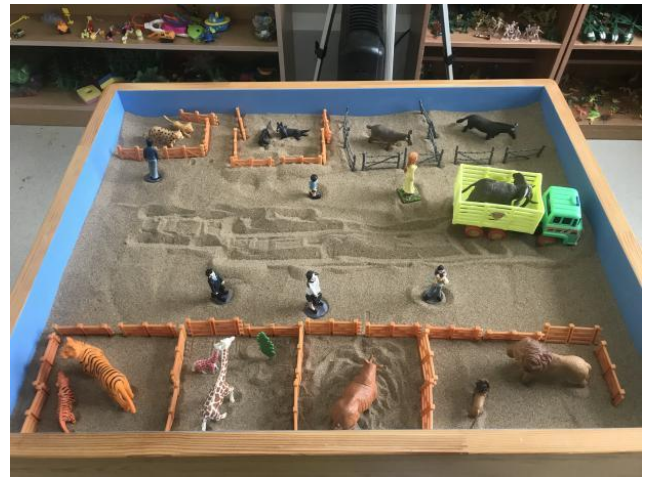

F5

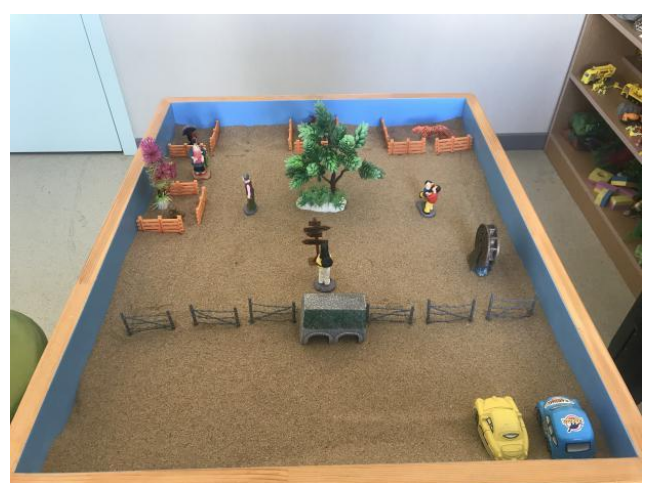

Z5

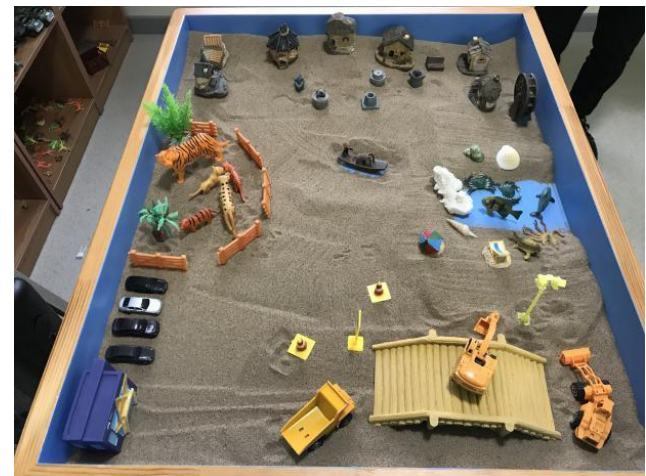

P5

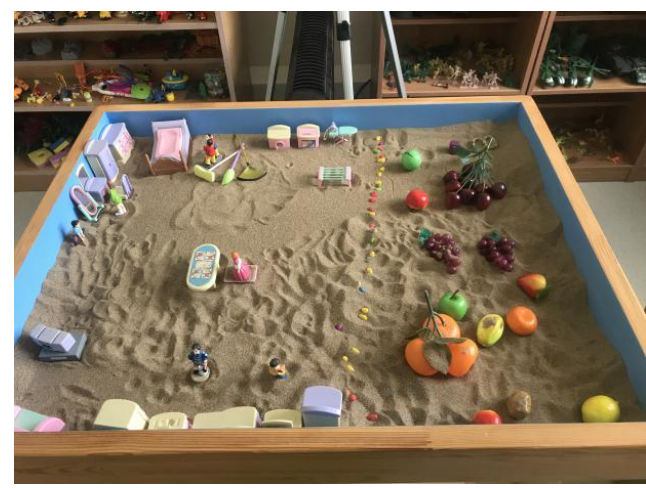

$\mathrm{H} 5$

图 3-5. 第五期沙盘图 
崔美玉 ·金龙男 ·金源荣 / 沙盘游戏治疗对小学生自尊水平的干预研究

\section{第五期分析:}

$\mathrm{F}$ 学生: 和前几次的沙盘不同, 制作过程看起来非常平静。在沙盘中放了许多动物, 大多 数动物都是成双成对的。自述到: “这次沙盘我想展示的是动物园, 虽然没有去过动物园的 经历, 但通过观察和想象, 认为动物园里的场景应该是这样的。将动物放置在动物园的两个 相互对称的地方, 中间有长长的路可以让人们来回参观动物。在这个动物园里最喜欢的是大 象和长颈鹿。” F 学生将沙具摆放的依然是上下对称的情境, 并且将最喜欢的大象放在中间 偏右的位置，可以非常清楚地看到只有在长颈鹿的围栏里摆放树木，这也是在后期咨询师需 要着重分析的部分。长颈鹿象征的是吉兽, 也象征着太平盛世 ${ }^{[14]}$ 。 $\mathrm{F}$ 学生潜意识领域里, 在 长颈鹿周边放了树木, 沙具中 “树木” 是生命的象征, 体现了 “保护” 和 “滋养” 两种元素。 $\mathrm{F}$ 学生用 “树木” 来保护 “长颈鹿”, 说明在潜意识领域, 希望得到安稳太平。大象是勇气、 博学的巫师和贤者的原型, 它有狮子般的勇气, 更象征着勇敢的酋长之相, 可知大象体现的 是人格的个性化。尽管在这次沙盘作品中出现了 “大象”、“长颈鹿” 两个象征积极的沙具, 但布置的沙具位置依然刻意呈现为对称状态, 说明产生了一些主动解决自身困扰的意愿, 并 正在努力解决着。

$\mathrm{P}$ 学生:在制作沙盘时, 更多了思考与体验, 制作沙盘作品的时间也随之变长了一些。在 选择第一个沙具黄色木质桥时, 尤为谨慎。前后思索了好多次后, 慎重地将桥放在了右下角 处, 并在桥梁附近放了好多施工车, 表示这个部分是正在建造桥梁的施工地。桥梁放置在意 识和潜意识联系的部分, 并在桥梁周边布置施工现场是一个积极的现象。说明正尝试在意识 与潜意识之间进行联系。其次, 在沙盘的上方部分, 第一次出现了大片的部落。在左侧则用 一连串的围栏, 将危险的猛兽围了起来。野兽有着凶猛攻击的象征, 在左侧潜意识部分呈现 野兽并将野兽围在围栏里的, 可以说明在 P 学生的潜意识里也存在着危险的一面, 但这一面 被深深地埋在潜意识中, 也在极力控制着自己冲动的一面。在沙盘的中央可以看到一艘小船,

\footnotetext{
[14] 하은혜, 곽진영, 김효식. 미술치료의

이해 [M]. 서울: 교육문화출판미디어그룹학지사 (韩国), 2019.
} 
Journal of Symbols \& Sandplay Therapy, Vol.12 No.2.

说这个小船在小河里。在离小河不远的右侧可以看到一大片海洋生物, 学生 P 表示这个地方 表示大海。在这期做沙盘时面带微笑, 移动沙具时还停唱几句歌显得很有趣很安逸。沙盘中 出现了河和海的场景, 但是河流和海洋是断开的, 船漂浮在河的中央, 但河的空间非常小, 小船几乎无法移动。这表示 $\mathrm{P}$ 学生仍然需要对潜意识进行及进一步深入的探索, 并扩展一定 层面到意识状态里。

$\mathrm{Z}$ 学生: 刚进入公园有一个指示牌, 正站在指示牌前寻找到达目的地的路。中间是一棵硕 大的乾坤树。乾坤树是北欧神话中的宇宙树, 象征生命泉、永远的生命和不死 ${ }^{[15]}$ 。以这棵 树为中心的四个方位有四种人。无意识可以说是强调了四个方面，但同时也出现了指示牌， 说明在无意识中渴望他人对自己的指引。树的右侧有嬉戏打闹的孩子们, 左侧则是前来观光 的旅客。与之前不同的是, 之前的自我像都是面朝玩要的孩子，但这一次的自我像却看着指 路牌。Z 学生一直是很难表达自己的情绪, 总是想做一个 “乘” 孩子, 但在无意识中也表现 出对需要叛逆或大胆提出自己主张的渴望。

$\mathrm{H}$ 学生: H 学生用彩石大致将沙盘的整体分为了两个部分。表示这一期她想呈现一个与之 前不一样的沙盘作品。在沙盘的左侧放了很多的家具, 并表示左侧是房子里面的场景, 并在 里面放了几个人物， $\mathrm{H}$ 表示这些人都在做自己事情。在沙盘的右侧，放了许多水果，表示那 里是房子外边, 并在沙盘的右上角买了许多宝石。用彩色小石子分成的两端, 左端为潜意识, 右端为意识领域。但可以看出此处并非出现人格化的特征或相互作用的形式。沙盘中有吵闹 的一对小孩、看镜子的小孩、正一个人吃饭的小孩、独自站着的小孩等，这些人群都是一个 人孤单的站着, 没有任何的相互作用及互动。还有一个小女孩在沙盘中央一个人吃饭, 可以 推断出在现实生活即意识中也是孤苦伶仃的状况，而这种情绪在同伴关系和人际关系中会带 来一定困难。在咨询中曾表示, 虽然自己对朋友尽自己努力去与他们相处, 但总觉得朋友对 自己存有误会, 不喜欢自己, 甚至排斥自己。从来访者的自述中可以看出, 来访者与同伴之

${ }^{[15]}$ 진쿠퍼 (J. C. Cooper). 세계문화상징사[M]. 서울:까치 (韩国), 1994. 
间的关系并不良好, 会导致来访者的自尊水平下降。个体的同伴关系直接影响个体的自尊水 平。 ${ }^{[16]}$ 这是 $H$ 学生具有以自我为中心看待事物的心态, 并可能暗示着缺乏自尊感。

\section{6）第六次沙盘游戏治疗干预过程分析}

第六期沙盘中, $\mathrm{F}$ 学生没有制作任何作品, 而是玩一场酒沙和耕田的游戏, 图片是当 $\mathrm{F}$ 学 生咨询技术时候的场景; P 学生制作的是一处旅游景点; Z 学生制作的是乡下路的情景; H 学生用围栏把沙盘分成五个部分, 并说每个空间都有各自的功能。

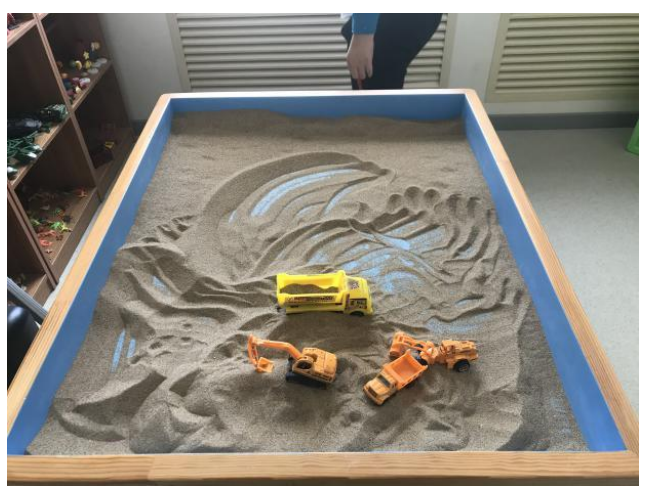

F6

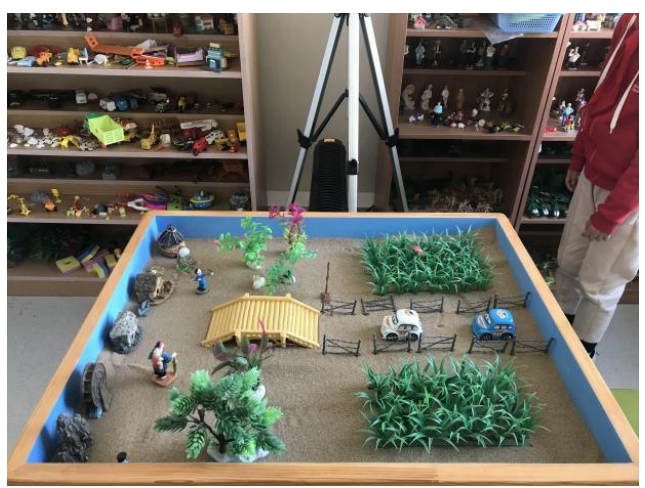

Z6

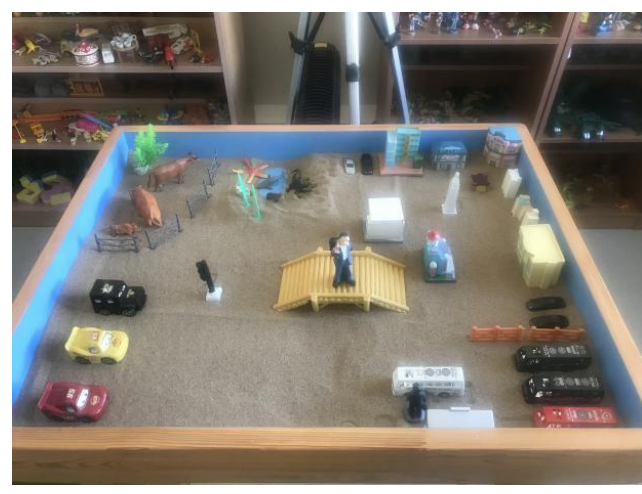

P6

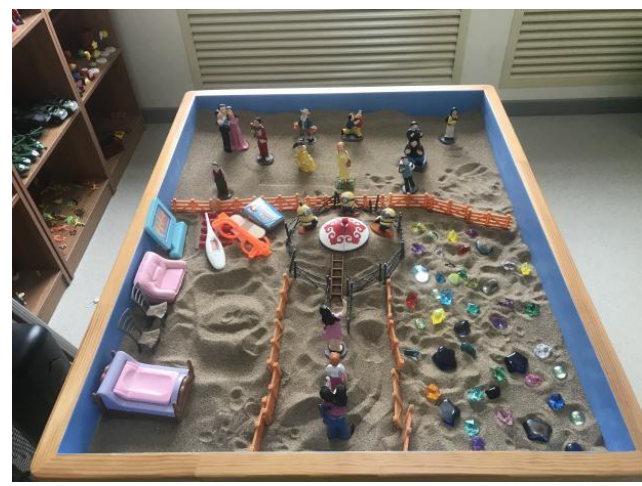

H6

图 3-6. 第六期沙盘图

[16] 单楠. 亲子关系、同伴关系、心理韧性对青少年自尊的影响 [D]. 济南: 山东师范大学, 2017. 
Journal of Symbols \& Sandplay Therapy, Vol.12 No.2.

\section{第六期沙盘分析：}

$\mathrm{F}$ 学生: 来访者主动提出了, 自己在选择沙具时存在的困扰, 并表示不想制作与以前重复 的沙盘。为了在更舒适放松的情况下进行咨询, 咨询师提出这次可以在不放置任何沙具的情 况下进行咨询, 如果在咨询的过程中发现了想放置的沙具, 可以随意放到沙盘中。F 学生不 仅大胆地讲出了自己在制作沙盘时选择沙具的困扰，也主动使用双手直接触摸了沙盘中的沙 子。可以看出, $\mathrm{F}$ 学生的行为表现比之前放松了许多, 也不再克制隐藏自己内心的感受, 勇 敢地尝试表达, 是一种自尊感提高的表现。在咨询师交流时, 会不自觉地触碰沙子, 并反复 用手把沙子抓起来再放下。虽然在本次咨询中比以往咨询时使用的沙具数量较少，但强行将 沙具摆放成对称状态的现象显然消失了, 这是不再抗拒去探索更多内在的 “自我”, 主动参 与咨询的表现。这次使用的沙具为 2 个大卡车、 2 个挖掘机, 并放在沙盘的下半部分。在沙 盘作品中可以看到，在制作时进行了数次的翻沙和耕田，并在沙盘的上半部分有很多用手划 过的痕迹, F 学生称这些划痕形态让他联想到了翅膀。在这个过程中, 玩了一场酒沙和耕田 的游戏, 该现象在过去的农业社会可以看作是为新起点做准备的过程, 象征着春天的到来, 万物复苏，准备新的挑战。在对沙盘中的划痕讲到，这使他联想到了岛儿的翅膀。在沙盘游 戏治疗中, 鸟象征着自由、神圣等, 说明渴望在家庭生活和学校生活带来的困扰中得以解脱。

$\mathrm{P}$ 学生: 来访者在沙柜前来回走动犹豫之后, 首先拿起的是木质桥梁和桥梁上的小人。之 后用手挖了一个小湖, 称为海。其次拿起小车, 在下方放置着说, 这里是停车场。在讲解过 程中, $\mathrm{P}$ 学生着重讲到了沙盘中的海和海洋动物, 还讲解了关于沙盘中的故事。在沙盘制作 中可以看出, P 学生对沙盘的探索与了解基本结束, 其中下半部分停车场的出现, 说明在潜 意识和意识中都在进行调整、休息和整顿, 沙盘整理得井井有条, 安置稳定。根据班主任的 反馈可以知道, 在这几期咨询后, $\mathrm{P}$ 学生最近努力调整自己的情绪。班主任还说, 进行沙盘 游戏治疗后, 从未和他的同学吵架, 同学们也对 $\mathrm{P}$ 学生的评价有所改变。从 $\mathrm{P}$ 学生的人际关 系上的好转现象与以往研究中的人际关系与自尊的相关上可以推断出 ${ }^{[17]}, \mathrm{P}$ 的自尊水平有所

[17] 刘广增等. 中学生心理素质与同伴关系的研究: 自尊的中介作用 [J]. 2016，39（6)：1290-1295. 
崔美玉 ·金龙男 ·金源荣 / 沙盘游戏治疗对小学生自尊水平的干预研究

提升，正在通过心理活动和内在探索，“自我”走向成熟。

$Z$ 学生: 以激动的表情和语调说在周末第一次尝试去做新的事。当自行车坏时, 照旧有托 父母或放弃的倾向, 但自己主动拿去修理厂进行维修。说通过这次事件, 第一次尝试去做之 前不敢做的事情, 不仅觉得没有比想象的那么难, 而且心情也很好。从自述中可以看出, 在 认识和探索自己的过程中, 还表现出试图改变自己的欲望。这一期沙盘中, $Z$ 学生首先在中 央放了一个桥梁, 之后在右下方和右上方放了草坪, 并解释道这是稻田, 再从沙具柜冲取很 多围栏插在 “稻田” 的两边, 在其中放两辆汽车, 显示为道路。最后在最左侧放草屋沙具, 说是一个村庄。汽车正在驶向潜意识领域的左侧。汽车象征着动力, 可以认为是进入潜意识 的推动力。桥梁连接意识和潜意识领域, 可以看作随时都安全往返的表现。每次沙盘都显得 非常整洁和工整, 但这期沙盘中的一个围栏显示倒塌, $Z$ 学生也认知到了这个部分, 但表示 没有必要刻意去把围栏摆正。可以看出, 从完美的性格中有所摆脱的现象。植物里有虫, 昆 虫虽有可能成为害虫, 但也可以成为益虫。从整体的沙盘来看, 期待会转变为积极的一面。

$\mathrm{H}$ 学生: 将沙盘分为五个部分, 这表示可以看作为第五元素, 它代表了物质的最纯净的本 质 ${ }^{[18]}$ 。这纯净的本质在炼金术中被称为 Aether ${ }^{[1]}$, 在分析心理学中, 可被视为 “自我”。这 种 “自我” 总是以积极的形式出现, 并引导心理活动即内心旅行。但由于它是抽象的和象征 性的, 因此人们很难认知和跟随。来访者自述到: “这是一个挑战吃辣椒比赛, 中间鼓起来 的沙子是房子, 那里有很多辣椒, 上面的 3 个小黄人正在看家。下面这一排人是来挑战这个 比赛的参赛者, 第一位上场的是一位孕妇, 如果这孕妇挑战成功的话, 会在这个右侧宝石里 选择一颗作为战利品; 如果挑战失败, 那么就会送到左侧救护营里进行治疗。上面那些人是 来观看这场挑战赛的群众。” 在 $\mathrm{H}$ 学生的沙盘中 Aether 是中央的部分, 说道: “这里的容器 里有辣椒。” 这里的食物可以象征使人壮实成长, 且可对母性情结对抗。想要靠近食物的孕 妇也同样跟自身母性情结有关联, 表达着潜意识里希望可以直接面对母亲的欲望。与同伴的

${ }^{[18]}$ 진쿠퍼 (J. C. Cooper). 세계문화상징사[M]. 서울:까치 (韩国), 1994. 
Journal of Symbols \& Sandplay Therapy, Vol.12 No.2.

关系一直是困扰 $\mathrm{H}$ 的最大的问题, 但在表达中发现了与以往相互矛盾的地方。之前的咨询中, 一直主张着其他同伴对自己不是很喜欢, 但在这一期咨询中, 说到自己觉得所有人都很喜欢 自己。在自述中可以看出与之前的表达有所出入, 与同伴的关系是 $\mathrm{H}$ 学生长期以来的烦恼, 但这一期对自己人际关系的过于积极地表达, 与长期以逃避的态度参与咨询的状态来看, 这 是有意回避现状的现象。

\section{7）第七次沙盘游戏治疗干预过程分析}

4 名来访者来到沙盘室之后都表现出主动, 积极地状态。在本期沙盘中 $\mathrm{F}$ 学生制作的是一

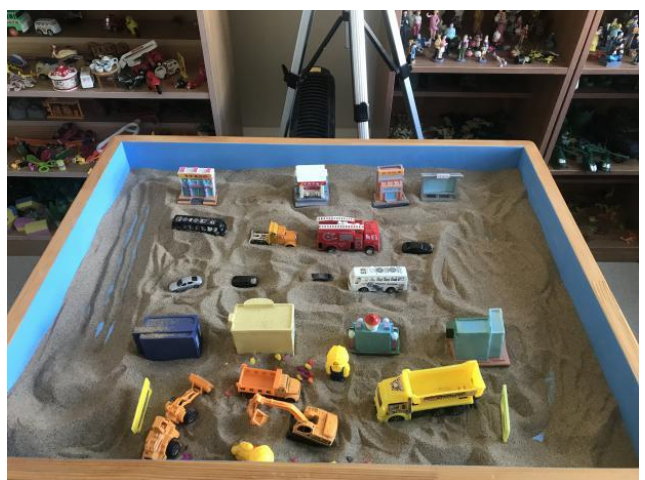

F7

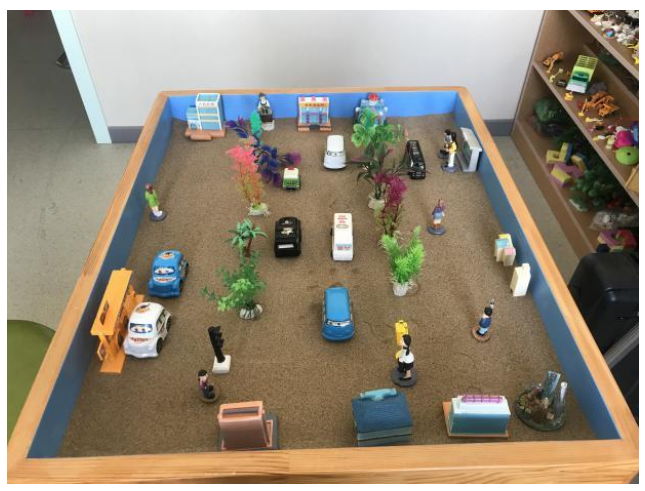

Z7

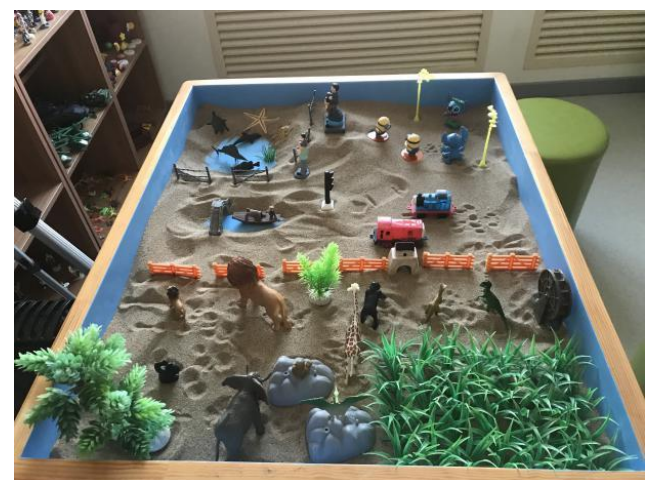

P7

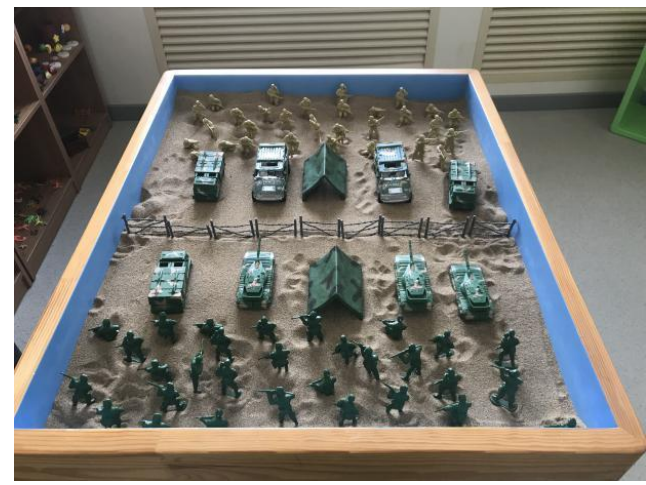

$\mathrm{H} 7$

图 3-7. 第七期沙盘图 
崔美玉 ·金龙男 ·金源荣 / 沙盘游戏治疗对小学生自尊水平的干预研究

个城市和城市后面的施工现场, 在过程中大部分注意力都用在制作施工现场; P 学生把沙盘 用围栏分成两半, 下方为动物园, 因为有危险的动物所以用围栏隔开, 上方为游乐场; $Z$ 学 生制作的是城市中的一块, 但可以看出 $\mathrm{Z}$ 学生的沙具数量和沙盘使用面积明显增加; H 学生 制作的是两个军队正在进行交战的场景。

\section{第七期分析:}

$\mathrm{F}$ 学生: 今天沙盘作品的内容与之前第二期、第四期做过的作品相似, 呈现的都是一座城 市的情境。但不同的是出现了前几期从未出现过的 “小河”。用手在左侧画出几道杜, 表示 这个部分是城市周围的一条小河, 并对作品的小河部分感到非常的满足。还指着右上角说: 太阳照射着大地。右上方为目标领域, 在已有沙盘游戏治疗象征手册中提到, 太阳是先照自 己, 然后照射周边 ${ }^{[19]}$ 。说明在潜意识心理活动中, 先体验自己的内心, 后为回想周边环境以 及人际关系等。水和火 (太阳) 的出现是正相反的两个方向, 象征着两极对立原则, 通过以 上的心理活动, 启示体验自己的潜意识以及寻求潜意识引导的目标。

$P$ 学生: 进咨询室之后没有直接去做沙盘, 而是表达出想和咨询师聊一下自己最近领悟的 几点。“老师, 最近的咨询让我想了很多。我觉得一般容易发火、发脾气的人通常在日常生 活中, 经常说脏话, 之前我好像自己也是这样的, 所以我决定改掉说脏话的话习惯的话, 我 也能过成为一个性格不错的人。那么, 我身边朋友自然会变得比现在多。是嘛, 老师? ” 通 过 P 学生的这番话可以了解到, 非常投入到这几期的咨询中, 在咨询中体验反思的过程较多, 因此, 咨询效果也是较好的。一番交谈结束后, P 学生开始了第七期的沙盘游戏治疗, 他在 沙柜前选了水车, 篱笆, 树木和动物等。水车是利用水作为驱动力将谷物压碎的设施。动物 聚集在下半部分。诸如草, 树和石头之类的自然物体的共存。恐龙的出现, 可以看作是经典 原始和先验的象征, 也可以看作是试图达到更深层次的潜意识的元素。

${ }^{[19]}$ 진쿠퍼 (J.C.Cooper). 세계문화상징사[M]. 서울:까치 (韩国), 1994. 
Journal of Symbols \& Sandplay Therapy, Vol.12 No.2.

$Z$ 学生: 学生自述到: “通过本次作品我想呈现的是一条路, 首先我用几棵树排列出了一条 可以双向通行的一条非常宽的路, 汽车双向行驶, 在意识和潜意识的领域自由来往, 似乎正 在进行对潜意识的探索, 并呈现在意识领域。这样的场面可以看出是走向积极变化的过程。 然后在路的两旁放置了过路的行人。这些行人非常准守交通规则，但沙盘的下端有一条没有 呈现出来的斑马线, 其两端各有一个红绿灯, 控制着行人的状态, 行人正在看着红绿灯, 准 备绿灯开启后过马路。左下角是一个加油站, 这里有两辆汽车正在有序的加油。” 通过 Z 学 生的描述可以看出, 左下端是一个加油站, 象征动力的源泉。在潜意识领域的探索过程中会 面临让自身感到不适的现象, 这时动力的源泉会促进 Z 的充分探索带来有利条件出现了很多 次例如 “有序、“准守” 等非常有体系有规则的单词, 可以看出 Z 学生的内在性格也是如此。 之后说她的大部分行动都是出于他人的视线或判断为衡量尺度。

$\mathrm{H}$ 学生: 在沙具柜前想很长时间之后把沙具柜中的所有军人沙具全部拿到沙盘中。然后她 又把栅栏, 坦克, 军用汽车和军用帐篷等等都拿到沙盘中。用围栏分画出黄队和绿队, 绿队 与黄队的所有配备物资是相等的并且布置的位置是一一对应的, $H$ 学生称战争已经开始。有 意将整个沙盘分为上下两个部分并形成鲜明对称图案, 这表达了紧张的情绪。并且与其他来 访者呈现的类似战争的沙盘作品相比较, 在本次作品中, 将战士都放到了栅栏, 坦克等物体 的后边, 并很好地隐藏起来。在激烈的战争过后死伤惨重, 无一幸存者。觉得战争是一件有 趣的事情, 但自己不想参与其中, 原因是危险。在自述中可以了解到, 遇到困难时也是这样, 比起勇敢面对困难解决问题，更会选择以各种方式逃避困难，不愿意表达真是的想法。在人 际交往中的消极体验, 在本次沙盘作品中以 “这里战争中的每个人都战死了。” 等人格化的 形式表现出来 。

\section{8）第八次沙盘游戏治疗干预过程分析}

在第八期沙盘中 $\mathrm{F}$ 学生制作的是跟第一期制作的沙盘极其相似, 但 $\mathrm{F}$ 学生制作的战争场面 始终是对其的状态，并没有真正的 “开战”。P 学生在本期大部分时间用于制作沙盘, 制作 


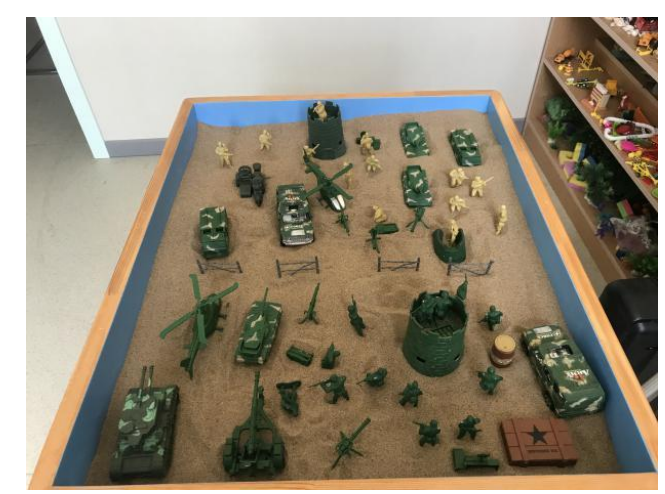

F8

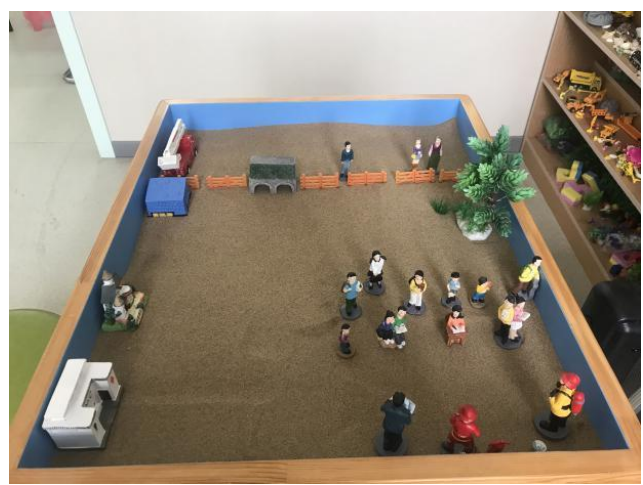

Z8

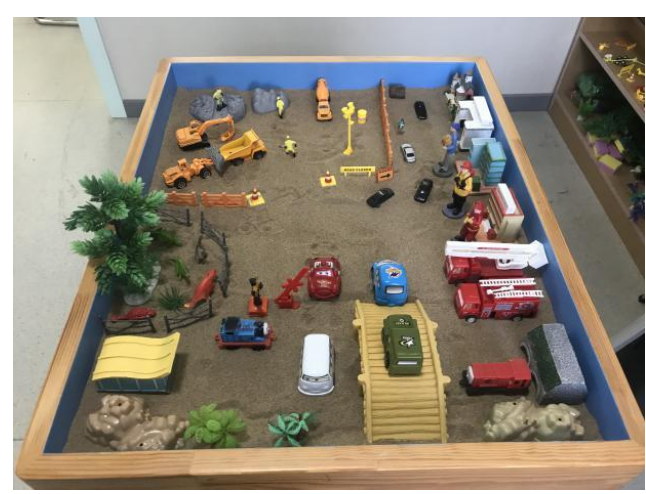

P8

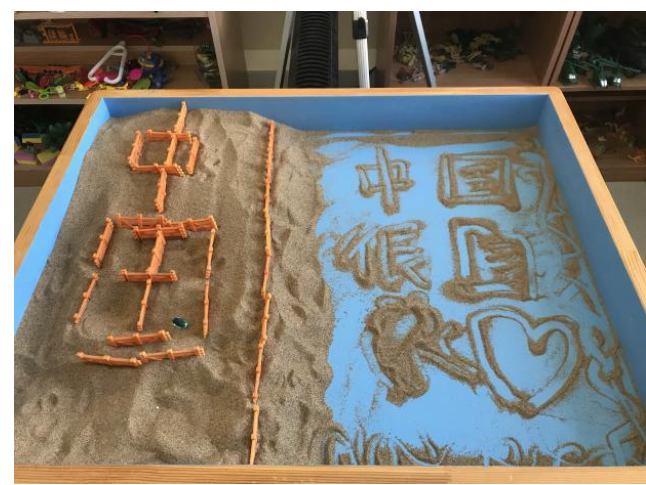

H8

图 3-8. 第八期沙盘图

城市边缘的一角; $Z$ 学生制作的是校园里的场景; $H$ 学生在本期用围栏和沙子写字。

\section{第八期分析:}

$\mathrm{F}$ 学生: 咨询师的安静陪伴在 $\mathrm{F}$ 学生的身边, 比之前主动提出的问题也较少。咨询师的变 化让 F 学生感到非常的不安。第一回期的场面与第八回期相似。潜意识的心理活动是危险的, 想起激烈情绪反应和过去的记忆, 则再现紧张的状态和对峙的状态是常见的退行过程 ${ }^{[20]}$ 。战 争场面也可以解释为, 未达成统一结构而努力的过程 ${ }^{[1]}$ 。

${ }^{[20]}$ 이부영. 분석심리학 [M]. 서울: 일조각 (韩国), 2011 
Journal of Symbols \& Sandplay Therapy, Vol.12 No.2.

$P$ 学生: 在各个小的细节很用心, 尤其对栅栏里面的施工现场格外用心。建筑的范围扩大 和工人的出现，表示内部工作已经扩大，个性化元素正在向着积极方向制定。在完成左方的 小森林时, $\mathrm{P}$ 学生表示看着这个部分感到莫名的不舒服, 但是这种不舒服不知从何而来。小 森林里放置恐龙后的更为如此。恐龙被困在潜意识的领域。恐龙是未知领域, 需要不断努力 去探索和挖掘, 潜意识的工作既困难又繁重。尽管如此 P 学生仍在不断努力去面对和尝试探 索潜意识的信息。放置桥梁, 各个建筑物和消防车、云梯车后看了看沙盘, 觉得还是缺点什 么。仔仔细细地看了一遍沙盘后, 到沙具柜拿栅栏给小森林搭上。P 学生说看沙盘不舒服的 原因是这部分，感觉这部分像自己不愿放开的一面。

$Z$ 学生: $Z$ 学生的沙盘作品, 以上部分的围栏为界限, 呈现为上下两个部分, $Z$ 学生说她想 呈现的是校园里的场景。在意识的领域中表现出学生们学习的场面。据 Z 学生的诉说中可以 看出想做什么事或者对提问的回答往往需要很长时间, 会给他人带来一种压抑和误解。在学 校也应该有这样的现象。Z 学生的沙盘中的大部分沙具集中在右下端，自述到：“右下端这 里是消防员为学校学生们普及消防知识, 做消防演练的场景, 消防员叔叔站在前面进行讲 解。”在咨询师问道 Z 学生的自我像在哪里时, Z 学生回答道: “我是最前面正在进行思考 的这个女孩子，”咨询师：“你在思考什么呢？” Z 学生：“刚刚消防员叔叔问了一个问题， 我在思考怎么才能既快速有正确的答案让所有人满意。” 我们可以看到, $Z$ 学生认识到自身 消极的经验, 并对这种行动模式进行补偿, 认识到变化的必要性。她为忧虑的自己列出了安 全守护的象征消防官、灭火器等沙具, 引导 Z 学生着对变化的安全感。

$\mathrm{H}$ 学生: 用手将沙子全部归拢到沙盘的左侧, 把沙盘的右侧部分的地不呈现出来。 $\mathrm{H}$ 学生 走到沙具柜前选择了较多的栅栏放到了沙盘中, 并使用这些栅栏在左侧沙子区域勾勒出了大 大的中国两个字。在潜意识领域的中国，用围栏组成的，围栏限制的意义也有保护的意义， $\mathrm{H}$ 在潜意识部分用围栏组成了中国的模样, 可以说明 $\mathrm{H}$ 学生渴望对自身进行积极地探索, 并 表达出在 $\mathrm{H}$ 学生的潜意识中, $\mathrm{H}$ 学生需要被他人保护的心理。在沙盘的右侧 $\mathrm{H}$ 学生则用剩余 
的甚少的沙子, 用手描绘出了中国很棒的字样, 下面用沙子表现出心的型状, 在周围用大拇 指表现边缘。在右侧意识领域中的中国很棒和我心是由沙写出。 $\mathrm{H}$ 学生的中国可以代表自己 内心，意识中表现出自己很棒很好。

\section{9）第九次沙盘游戏治疗干预过程分析}

在本期咨询中 $\mathrm{F}$ 学生制作的是跟第五期相似的动物园场景, 但是可以看到细节部分有所改 变; P 学生呈现的是小镇场景; $Z$ 学生呈现的是农场的场景; $H$ 学生制作的是自己想象中的 农村模样。

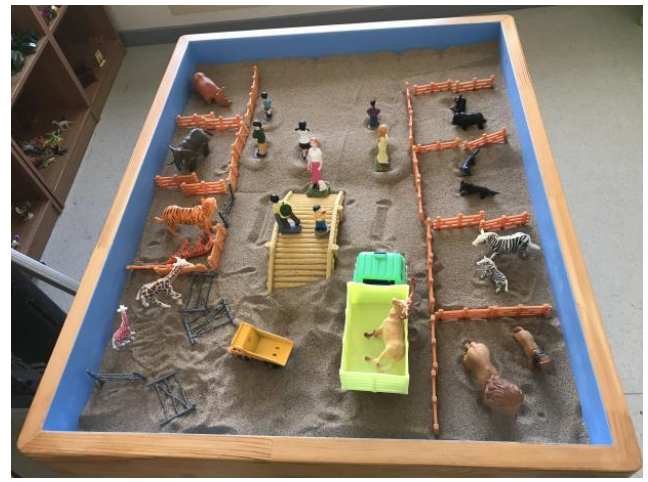

F9

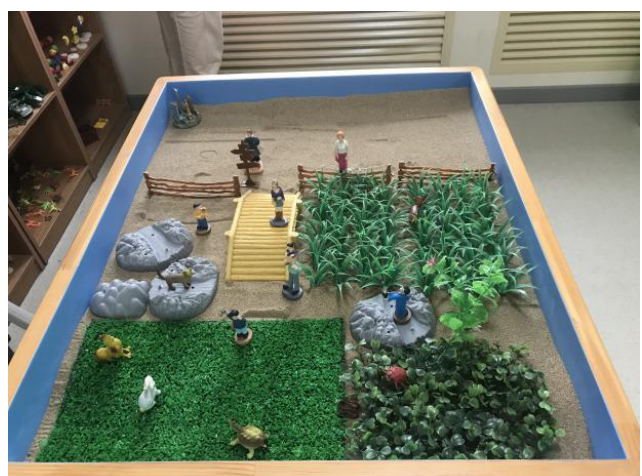

Z9

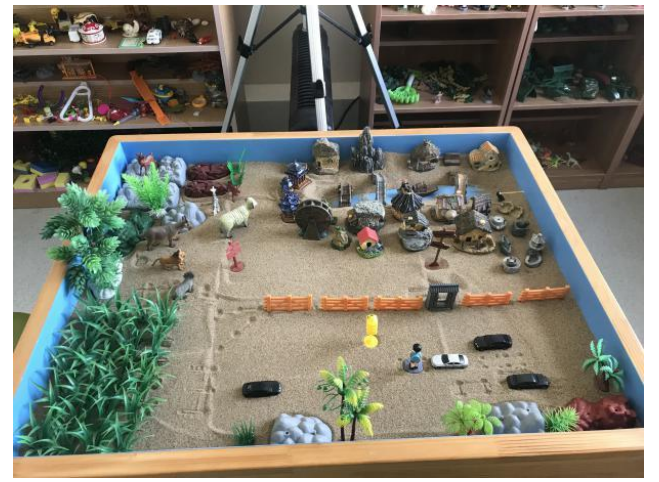

P9

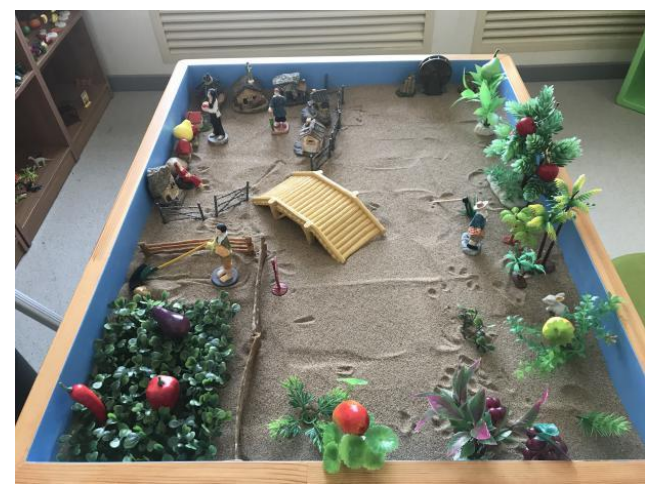

H9

图 3-9. 第九期沙盘图 
Journal of Symbols \& Sandplay Therapy, Vol.12 No.2.

\section{第九期分析:}

$\mathrm{F}$ 学生：首先, 沙盘的正中央出现了桥; 桥出现在沙盘中央, 桥是可以结合两个领域的象 征。其次, 在第五期出现的长颈鹿是圈在围栏里的, 但是在第九期出现的长颈鹿周围围栏是 开放的。最后, 是大卡车中的动物, 从第五期的大象变为驯鹿。则下方的驯鹿被载入卡车往 沙盘的上开去。驯鹿是被忽视的象征 ${ }^{[21]}$ 。由此可见, 这象征因家暴使其自尊感较低, 焦虑等 消极情绪所致无法准确认知和认识自己的价值, 更无法认可自己。所以卡车载着驯鹿, 从潜 意识领域往意识领域开去则象征着告诉自己已找到方向，可以理解为认识自己的过程。

$P$ 学生: 在放老宅的沙具柜前选了很多的老住宅放在右上方。用栅栏在中间分割了小镇和 小镇外的世界, 栅栏中间放置通往小镇的门, 并解释道这是连接小镇与镇外的一个通道。将 整个小镇安排在河的两侧，整条河路贯穿着整个村庄，通过这条河村里的来往比较方便。这 意味着可以更接近内部心理进行探索并迈向成熟。在上次的沙盘里, 受到足够控制的动物, 这一次没有围栏被释放自由出现，说明 P 学生可以适当地控制调整自己。

$Z$ 学生: 作品中出现了与第四期相同的植物沙具, 但不同的是本次的植物上方增多一些例 如昆虫, 蛇等动物。对自己的沙盘用复杂来形容, 前期咨询中说自己最不喜欢的状态是复杂 的状态，但这期 Z 说: “虽然觉得负复杂，但是可以接受”。可以看出通过长时间的沙盘游戏 治疗，Z 学生体验到心理上的稳定感。自述：“我很喜欢左下方这个部分，草坪上既有乌龟 还有兔子旁边还有小鸡, 虽然他们的生活环境都不一样, 出现在同一个草坪上看起来非常的 突兀，但是我看着这个部分没感觉很囬尬，反倒觉得很舒服，很和谐。”之前在对 $Z$ 学生的 介绍中讲过, Z 学生是一个极其讨厌复杂的孩子，但在本次沙盘作品中，可以看出沙具摆放 的没有规律错综复杂，小鹿甚至隐藏在草坪中，难以发现。当天沙盘表现出复杂的一面，与 以往的模式不同, $Z$ 学生也未对其复杂感到不适。沙盘中的动物并没有圈起来，可以看出 $Z$ 学生的各种性格和欲望试图与周围融合的表现。无意识领域中又出现了红色昆虫, 在无法看

[21] 檀名山. 象征学全书 [M]. 北京: 台海出版社, 2001 
出是积极与消极的情况下, 需要去保护它的存在。

$\mathrm{H}$ 学生: 在第九期的沙盘作品中, 在左上角呈现的是一座小镇, 并在右上角放置了一个水 车。小镇与外界以一座桥相互联系着 $\mathrm{H}$ 学生表示小镇里的人可以随意通往外界。村庄与外界 相连, 它不是分开的, 两个部分既有明确的划分也有着联系, 表示可以自由地来来去去。在 左下侧放了草坪, 并在草坪上放了许多果实, 并有农民伯伯看守着自己的种植的蔬菜。在其 余部分放置了很多果树, 果树上也结满了许多果实。 $\mathrm{H}$ 学生说看到果树上结满果实, 心理非 常开心。此外, 通过汗水和劳动进行自我生产的场景是潜意识中的补偿作用的象征。

\section{0）第十次沙盘游戏治疗干预过程分析}

除了 Z 学生的沙盘意外其他三个人的沙盘中都出现了混乱, 对齐和紧张的场景。对分离有 着焦虑的青少年来访者的沙盘中可能会出现紧张的场景, 对此类来访者的沙盘终结需要格外 谨慎 ${ }^{[22]}$ 。四名来访者都对沙盘游戏治疗的结束感到遗憾。咨询师跟来访者说今天是最后一次 之后, 并让来访者开始制作沙盘。 $\mathrm{F}$ 学生制作的是事故现场; $\mathrm{P}$ 学生制作的是军队对齐场景; $\mathrm{Z}$ 学生制作的是农场场景; $\mathrm{H}$ 学生在沙盘中放了很多爬行动物。

\section{第十期分析:}

$\mathrm{F}$ 学生讲到, 他制作的是事故现场, 周围来了很多救援队员实施营救。接着 $\mathrm{F}$ 学生在 沙盘左下角制作了施工现场, $\mathrm{F}$ 学生边把沙盘中的沙子放到施工队的卡车里, 边问咨询 师 “这一期咨询结束后还能继续来找老师做沙盘游戏吗？”。对沙盘游戏治疗的结束表 示很遗憾。F 学生的沙盘中出现了事故现场, 事故现场显示混乱场景, 代表着 F 学生对 沙盘游戏治疗结束所带来的不安情绪。但混乱的事故现场中有消防车和很多救援队员。 可以看出, 通过沙盘游戏治疗 $\mathrm{F}$ 学生对自身内面进行自我修复, 自己解决自身问题, 可以看作为成长。代表潜意识部分的左下方出现了施工现场, 可以看为为了找出新的

[22] 장미경. 분석심리학-모래놀이치료 [M]. 서울: 교육문화출판미디어그룹학지사 (韩国), 2017: 153. 


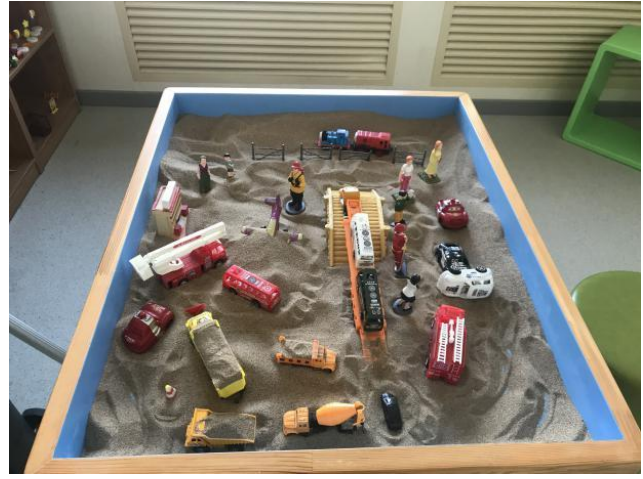

F10

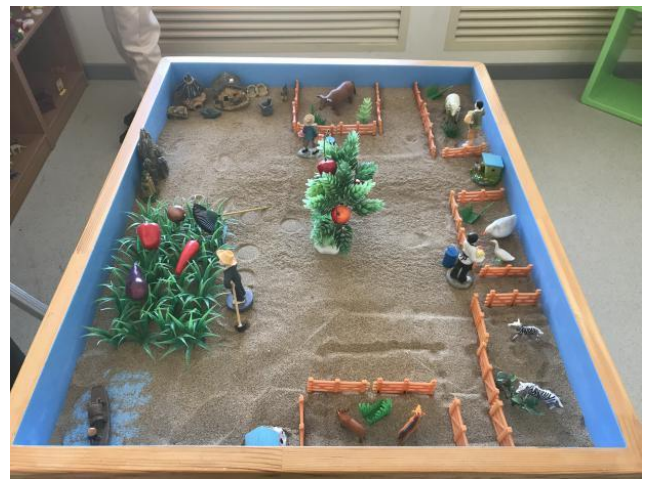

Z10

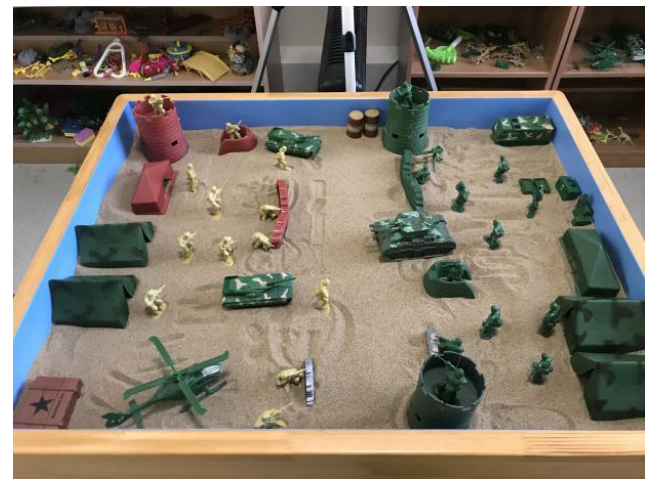

P10

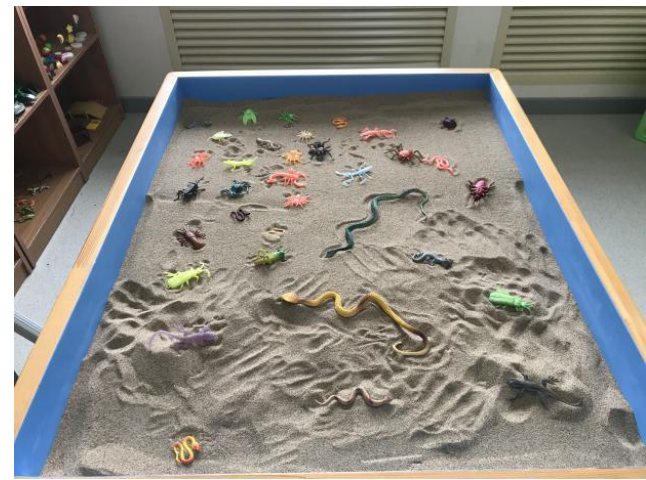

$\mathrm{H} 10$

图 3-10. 第十期沙盘图

问题并解决此问题而探索潜意识领域。

$P$ 学生: 注意到沙柜的最底层有军事用品以及军人, 随手拿起直升机、坦克、帐篷、军人 等一一放在沙盘上。一边放沙具一边演示战争的细节剧情。P 学生自述到: “这里即将开始 一场战争, 左方为我军则右方为敌军, 虽然战争还没开始, 但两方的状态非常紧张, 随时都 可能打起来。战争的最后是以我军胜利结束的”。一般情况下战争、对峙等情况, 就会认为 是消极的, 但根据《象征词典》, 可以看出战争需要寻找新的无秩序, 并在这种混乱中建立 
新秩序, 是一个统一的过程 ${ }^{[23]}$ 。需要统一的要素是自身消极的经验, 即父母自卑感、人际关 系、不安感、低自尊感等。这种情感在潜意识中会引起回避, 倒退, 不安, 痛苦等多种多样 而强烈的静止反应。但我们可以看到, 克服这种感情, 重新站起来才能成为另一个成熟的旅 程。P 学生表示非常遗憾这次是最后一次咨询, 回顾沙盘游戏治疗期间自己的表现, 表示在 这期间有不断成长。不断反思及时调整自己。在家和弟弟的关系变得友善, 在学校和同学们 的关系也友好。

$Z$ 学生首先选择了左侧的草坪, 在沙盘的中央放置了一个大树。制作过程中 $Z$ 学生非常注 重细节, 例如在草坪与树木上小心翼翼的固定了许多果实。Z 学生在沙盘的上边、右边、下 边都放置了在围栏里的动物, 每个动物的围栏里都有植物。最后 $Z$ 学生在沙盘的左下角做出 了小河, 小河里有一艘小船, 小船上有一位渔翁。与第一次的沙盘形成了鲜明的对比。由原 来被关着的牛身边出现了草, 人们自己看管动物。上期虫子的劳苦终于有了结果, 丰富的水 果和蔬菜是丰硕的象征。左下侧代表潜意识部分的河里出现了船和渔翁, 在沙盘游戏治疗中, 渔船与渔翁结合在一起, 用于象征在潜意识中进行深入探究的愿望的动力。象征透过更深层 次的潜意识去探索自身所成长的部分。 $Z$ 学生对自己制作的沙盘感到最满意的部分是动物们 看起来不孤单, 可见, $\mathrm{Z}$ 学生把自己的感情和状况投射到了沙盘中。对自己平时一到周末就 感到孤单的问题对咨询师求助, 并一起探讨解决方法。Z 学生说她正在寻找战胜孤独的方法。

$\mathrm{H}$ 学生说到: “老师, 这是最后一次了吗? 我还有很多想制作的沙盘作品, 好可惜呀! 之 前我一直害怕表达我内心的想法, 所以对我之前制作的沙盘作品不是很满意, 如果我能在快 一些适应的话, 我能做出比现在更满意作品的。” 咨询师表示, 如果今后 $\mathrm{H}$ 学生还遇到自己 不能解决的问题时, 随时可以寻求老师的帮助, 并结束了最后一次的咨询。在埃及, 金龟虫 和蚚蜴象征神的预知 ${ }^{[24]}$ 。蛇有双重象征, 也有治愈的象征 ${ }^{[25]}$ 。在埃及蝎子有守护者的角色 ${ }^{[26]}$ 。

[23] 檀名山. 象征学全书 $[M]$. 北京: 台海出版社, 2001.

[24] 진쿠퍼 (J.C.Cooper). 세계문화상징사[M]. 서울:까치 (韩国), 1994.

[25] 魏广东. 沙盘游戏治疗象征手册 [M]. 北京: 中国石化出版社, 2018.

${ }^{[26]}$ 檀名山. 象征学全书 [M]. 北京: 台海出版社, 2001. 
Journal of Symbols \& Sandplay Therapy, Vol.12 No.2.

在 $H$ 学生的沙盘作品中, 还出现了很多蝗虫。蝗虫象征灾难与破坏, 这说明 $H$ 学生对沙盘游 戏治疗咨询的结束有着不安情绪。

\section{2. 干预后自尊水平调查结果}

\section{1）干预后测试结果}

为了解干预后 4 名来访者的自尊水平是否有所提升, 沙盘游戏治疗干预是否对小学高年级 学生自尊水平有效, 对 4 名来访者的前测与后测进行了统计, 结果请看表 2 。

表 2. 前后测结果比较

\begin{tabular}{ccccccccc}
\hline & \multicolumn{2}{c}{$F(M)$} & \multicolumn{2}{c}{$P(M)$} & \multicolumn{2}{c}{$Z(M)$} & \multicolumn{2}{c}{$H(M)$} \\
& 前测 & 后测 & 前测 & 后测 & 前测 & 后测 & 前测 & 后测 \\
\hline 外表 & 2.00 & 2.50 & 2.00 & 3.00 & 4.00 & 4.75 & 4.00 & 4.00 \\
体育运动 & 2.33 & 2.67 & 3.67 & 3.67 & 2.30 & 3.33 & 3.33 & 3.67 \\
能力 & 1.67 & 3.33 & 3.00 & 4.00 & 2.33 & 4.50 & 3.50 & 4.00 \\
成就感 & 2.75 & 3.50 & 3.25 & 3.50 & 2.75 & 4.00 & 3.00 & 3.75 \\
纪律 & 2.00 & 3.00 & 3.50 & 4.00 & 3.75 & 4.25 & 3.00 & 3.50 \\
功德与助人 & 3.00 & 3.20 & 3.60 & 4.00 & 4.00 & 4.00 & 3.20 & 3.60 \\
自尊水平 & 2.29 & 3.53 & 3.17 & 3.70 & 3.18 & 4.20 & 3.33 & 3.75 \\
\hline
\end{tabular}

通过表 2 了解到, 4 名来访者干预后的自尊水平及各维度的平均得分明显高于前测。

来访者 $\mathrm{F}$ 学生的自尊水平从前测的 2.29 提升至 3.53 , 各维度分数也有所提升, 在各维度 上提高的幅度由高到低分别为能力、纪律、成就感、外表、体育运动及功德与助人。

来访者 $\mathrm{P}$ 学生的自尊水平从前测 3.17 提升至 3.70 , 干预后除了体育运动维度上的得分是 持平状态以外各维度的得分均高于前测得分。在各维度上提升的幅度由高到低分别为能力、 外表、纪律、功德与助人、成就感。

来访者 $\mathrm{Z}$ 学生的自尊水平从前测 3.18 提升至 4.20. 干预后除了功德与助人维度上的得分 是持平状态外, 各维度的得分均高于前测得分。在各维度上提升的幅度由高到低分别为能力、 
成就感、体育运动、外表、纪律。

来访者 $\mathrm{H}$ 学生的自尊水平从前测 3.33 提升至 3.75 。干预后除了外表维度得分是持平状态 外, 各维度的得分均高于前测得分。在各维度上提升的幅度由高到低分别为成就感、能力、 纪律、功德与助人、体育运动。

\section{2）干预后效果评估}

\section{（1）第一、 $F$ 学生的效果评估}

班主任评估: $\mathrm{F}$ 学生与之前相比课堂上表现越来越趋向积极, 在课堂上尝试主动举手发言, 参与课堂活动。作业完成效果比之前也有了很多改善, 如会及时上交作业, 作业的准确度提 高等现象, 在咨询后其他科任老师也有反应到 $\mathrm{F}$ 学生在学业方面的表现与以往大有不同。

父母评估: 咨询后 $\mathrm{F}$ 学生在家里的表现有了变化, 据观察孩子之前非常依赖补习班, 放回 后的学习可以说除了补习班以外就没有了。但通过咨询发现孩子到家之后会主动拿出做过的 练习题进行反复的思考, 试图主动学习, 因此父母与孩子之间因为学习而产生的矛盾也逐渐 变少了, 孩子还尝试与父母进行深层的交流。

自我评估: 通过咨询发现只要我尝试去听老师们讲的课堂内容, 其实没有我之前想象的那 样那么难以去理解, 再加上课堂上老师对我的评价也变得越来越积极, 让我觉得好像其实并 没有我想象的那么差, 之前是努力不够。当集中学习时发现其实有好多有趣的科目, 像是语 文和数学让我感觉非常有意思, 当自己完成一道题时会很有成就感。

\section{（2）第二、P 学生的效果评估}

班主任评估: 最近对 P 学生的观察中发现, 与同伴的关系改善了不少, 之前班级同学在谈 论外貌相关的话时, P 学生一直保持沉默, 有时提到 P 学生的个子时虽然没有说到 P 学生的 敏感词, 但 P 学生也会表示非常生气, 甚至与同学发生争执, 但最近能看到 P 学生逐渐接受 
Journal of Symbols \& Sandplay Therapy, Vol.12 No.2.

了自己外貌, 并且不以为这是自己的劣势, 可以看出 $\mathrm{P}$ 学生欣然接受了自己外貌上的特点, 这也让 P 学生在同伴当中更受欢迎。

父母评估: 通过咨询可以发现孩子越来越开朗了, 在家里和弟弟的冲突也变了少一些, 主 动和父母交流学校发生的有趣的事情。可能是在学校与同伴之间的矛盾变少了, 才促成的这 样的现象。

自我评估：以前一直以为个子矮是我的劣势，但通过咨询发现个子高、个子矮都有各自的 优势和劣势, 所以觉得我的个子高低好像并不是我成为受欢迎的人的重要关键。而且发现比 起外貌帅气心灵美才是更重要的, 很多同学都说想和善良开朗大气的同学做朋友, 但没有同 学说要和个子高的同学做朋友, 所以觉得我应该多改一下我的性格, 而不是我的外貌，觉得 我长得还不错。

\section{（3）第三、 Z 学生的效果评估}

班主任评估: 咨询后在课堂上注意力有所提升, 并且尝试挑战新鲜事物, 在各方面的自信 心也有所提升。 Z 学生总是给人一种在很多方面都很优秀的印象, 从而导致 Z 学生非常畏惧 失败, 害怕在他人眼中自我形象会受到不好的影响, 但小学生中大多数受欢迎的孩子体育运 动很好, 但 $\mathrm{Z}$ 学生在体育运动方面不是很拔尖, 可能因为这个原因, 导致了 $\mathrm{Z}$ 学生不敢参加 运动项目。通过咨询后, 发现 Z 学生能够正确的看待失败, 也试图去挑战新鲜事物, 变化很 大。

父母评估: 之前孩子比较内向, 很少跟父母交流一些自己的内心想法, 父母与孩子的互动 也较少，但咨询过后孩子逐渐尝试帮助父母做些家务，尝试自己亲力亲为完成问题。最大的 转变就是之前 Z 学生比较依赖于父母, 大多数事情会按照父母的安排来做, 在遇到困难时会 向父母求助, 但现在 Z 学生越来越趋向于自己独立完成任务, 在做选择的时, 有时还会提出 
自己的建议和想法。

自我评估: 通过咨询发现其实尝试挑战新鲜事物并没有我想象的那么糟糕, 而且失败后的 结果也不是很糟糕的, 不会发生多么重大的后果。再加上再尝试完成新鲜事物后成功时, 它 带给我的成就感是非常强大的。

\section{（4）第四、 $\mathrm{H}$ 学生的效果评估}

班主任评估: 在纪律方面 $\mathrm{H}$ 学生由于从小得到父母的溺爱, 导致 $\mathrm{H}$ 学生非常的自我中心, 要求班级的同学要围绕着自己生活, 很少主动谦让其他同学, 忽略他人的感受, 纪律性较差。 但通过咨询, 可以发现 $\mathrm{H}$ 学生越来越考虑他人的感受，与他人相处时也努力去遵守人际交往 的基本规则，更是在上课时，会考虑到他人的感受主动维持班级的秩序，因此很多任科老师 反映咨询之后 H 学生课堂纪律非常好。

父母评估: 之前回到家后 $\mathrm{H}$ 学生不会跟父母提到学校的事情, 可能是因为与老师或同班的 关系不融洽, 现在 $\mathrm{H}$ 学生回到家经常谈论学校发生的有趣的事情和自己受表扬的事儿, 发现 孩子自尊感有所提升，对自我效能感提搞了很多。

自我评估：通过咨询懂得了合作的重要性，让我体会到了通过合作完成任务的成就感。咨 询中老师经常让我尝试进行换位思考。发现，其实我讨厌的事情其他同学也很排斥，像是上 课捣乱，妨碍老师上课，其实这对想认真学习的同学们带来很大的不良影响。我尝试在课堂 上控制自我, 老师竟然表扬我, 同学们对我的评价也有所提高, 发现其实在纪律方面我也不 是很差。

\section{3）追踪调查结果分析}

为了进一步了解干预对来访者的影响, 在经过 3 个月后对 4 名来访者进行了追踪调查测试, 
Journal of Symbols \& Sandplay Therapy, Vol.12 No.2.

表 3. 后测结果与追踪调查对比表

\begin{tabular}{ccccccccc}
\hline & \multicolumn{2}{c}{$F(M)$} & \multicolumn{2}{c}{$P(M)$} & \multicolumn{2}{c}{$Z(M)$} & \multicolumn{2}{c}{$H(M)$} \\
& 后测 & 追踪 & 后测 & 追踪 & 后测 & 追踪 & 后测 & 追踪 \\
\hline 外表 & 2.50 & 2.00 & 3.00 & 2.50 & 4.75 & 4.25 & 4.00 & 3.50 \\
体育运动 & 2.67 & 3.33 & 3.67 & 4.00 & 3.67 & 3.33 & 3.67 & 3.67 \\
能力 & 3.33 & 3.00 & 4.00 & 4.50 & 4.50 & 4.17 & 4.00 & 3.83 \\
成就感 & 3.50 & 3.00 & 3.50 & 3.50 & 4.00 & 4.25 & 3.75 & 3.50 \\
纪律 & 3.00 & 2.75 & 4.00 & 4.25 & 4.25 & 4.00 & 3.50 & 3.50 \\
功德与助人 & 3.20 & 3.60 & 4.00 & 4.40 & 4.00 & 4.00 & 3.60 & 3.60 \\
自尊水平 & 3.53 & 2.95 & 3.70 & 3.85 & 4.20 & 4.00 & 3.75 & 3.60 \\
\hline
\end{tabular}

其结果如下表 3 。

根据结果发现, 经过 3 个月来访者 $\mathrm{F}$ 学生、 $\mathrm{Z}$ 学生、 $\mathrm{H}$ 学生的追踪测试比后测水平有所降 低, 但降低幅度较小。其中 F 追踪测试结果比后测结果降低了 $0.58 ; \mathrm{Z}$ 学生追踪测试结果比 后测降低了 $0.15 ; \mathrm{H}$ 学生追踪结果比后测降低了 0.15 。并且来访者 P 学生的追踪测试结果 高于后测。数据结果可以了解到干预后的四名来访者自尊水平明显高于前测水平, 跟踪测试 结果虽然低于后测结果, 但可以看出高于前测水平。因此可以说明干预是有效的。之所以追 踪测试结果低于后测结果, 是因为放假期间存在许多因素影响, 其中可以看到 $\mathrm{F}$ 学生的自尊 水平下降幅度较大, 原因是因为 $\mathrm{F}$ 学生的特殊家庭背景导致。

\section{IV. 结论与研究不足}

\section{1. 结论}

本研究通过《儿童自尊量表》篮选出低自尊水平的 4 名来访者, 运用沙盘游戏治疗法进行 10 次干预后对来访者再进行《儿童自尊量表》测试, 结果显示各个维度均有明显的变化, 并三个月后的回访效果也良好。沙盘游戏治疗对小学生低自尊水平有显著干预效果。 
1. 沙盘游戏治疗有效提高小学生的自尊水平。通过观察和记录 4 名学生在沙盘游戏治疗过 程的作品的基本构成、自我像、箱庭作品的总体印象和沙盘的九个区域的表现，由初期的 静止趋向后期的动态, 沙盘游戏作品朝着积极的方向转变, 充分说明来访者心理的变化和发 展。来访者不受非言语的过程限制自由发展的空间, 用沙盘作品来表达自我感受, 从而促进 心理成长。

2. 咨询师在沙盘游戏治疗过程中无条件的尊重和接纳, 让来访者感受保护与自由的空间氛 围，传达支持与共情力量，从而达到干预效果的目的。

3. 通过沙盘游戏治疗前后对来访者的家长、班主任和同学的访谈了解, 来访者 4 名学生在 沙盘游戏治疗后明显表现出自信, 积极能量不断增加, 并将这种能量迁移到日常生活过程中。

\section{2. 研究不足}

1. 在调查研究中样本略少, 基于样本所得出的描述性统计结果, 在直接反映朝鲜族小学高 年级学生的整体平均自尊水平上存在差距。

2. 因沙盘主试者对沙盘咨询经验有限, 在沙盘操作和沙盘分析上存在些许不足, 在进行沙 盘主题分析时, 研究者作出的沙盘主题分析可能略显主观。

\section{参考文献}

최정희. 가정의 사회경제적 지위와 어머니의 양육스트레스 및 양육행동이 아동의 자아존중감에 영향을 미치는 경로 [D]. 首尔: 이화여자대학교, 2010.

李小龙. 离异单亲家庭初中生父亲在位对学习倦怠的影响: 自尊、心理弹性的链 式中介作 用和社会支持的调节作用 [D]. 荆州：长江大学，2019.

魏晓娟. 青少年自尊的发展特点及家庭影响因素研究 [J]. 青少年学刊 . 2016（3)：16-20. 
Journal of Symbols \& Sandplay Therapy, Vol.12 No.2.

황양선. 집단모래놀이치료가 다문화가정 아동의 학교적응과 자아존중감미치는 효과[D]. 首尔: 남서울대학교, 2019 .

진쿠퍼 (J.C. Cooper). 세계문화상징사[M]. 서울: 까치 (韩国). 1994.

하은혜, 곽진영, 김효식. 미술치료의 이해[M]. 서울: 교육문화출판미디어그룹 학지사 （韩国），2019.

魏广东．沙盘游戏治疗象征手册 [M]．北京：中国石化出版社，2018.

이부영. 이집트 신화[M]. 서울: 해바라기 (韩国), 2001.

沈贵兰. 城市小学儿童自尊异质性背景下的社交焦虑在自尊和同伴关系间的中介 作用 [D].

成都：四川师范大学，2017.

홍숙기. 마리 루제이 폰프란츠[M]. 서울: 한국융연구원 (韩国), 2017.

손영호. 마이너리티역사-혹은 자유의 여신상:살림지식총서[M] : 서울: 살림출판사, 2003.

单楠. 亲子关系、同伴关系、心理㓞性对青少年自尊的影响 $[\mathrm{D}]$. 济南: 山东师范大学，

2017.

刘广增等. 中学生心理素质与同伴关系的研究: 自尊的中介作用 $[J] .2016 ， 39(6)$ : 12901295.

이부영. 분석심리학[M]. 서울: 일조각 (韩国), 2011.

檀名山. 象征学全书 $[\mathrm{M}]$. 北京: 台海出版社, 2001.

장미경. 분석심리학-모래놀이치료[M]. 서울: 교육문화출판미디어그룹학지사 (韩国), 2017: 153

투고일 : 2021. 09. 27

수정인 : 2021. 11.25

게재확정일 : 2021. 12.06 